\title{
Evolutionary history of a Scottish harbour seal population
}

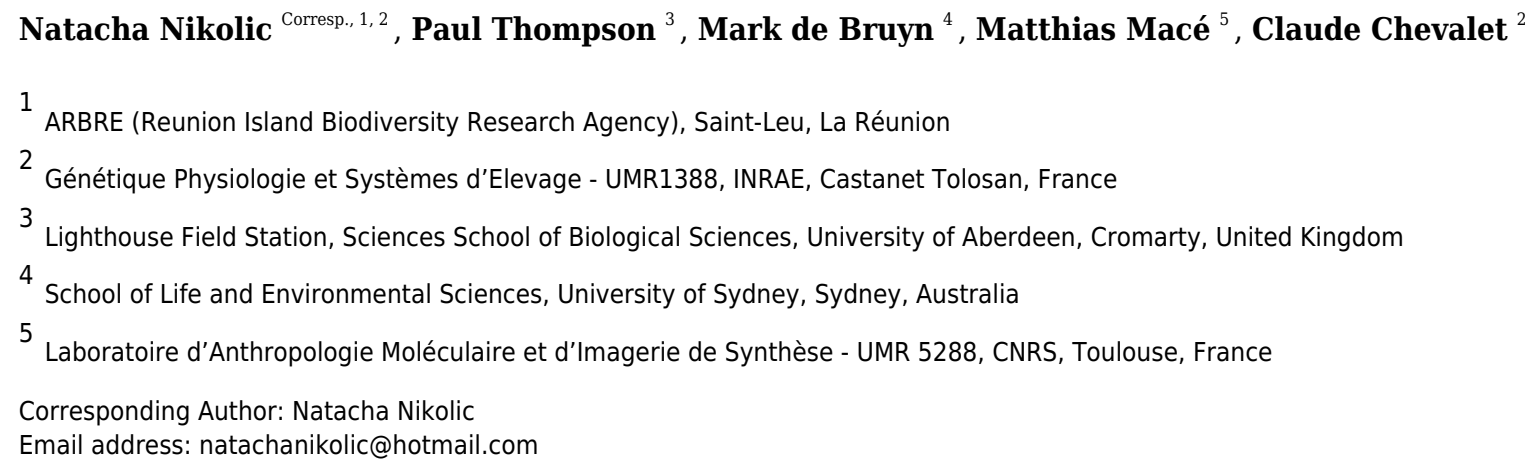

Efforts to conserve marine mammals are often constrained by uncertainty over their population history. Here, we examine the evolutionary history of a harbour seal (Phoca vitulina) population in the Moray Firth, northeast Scotland using genetic tools and microsatellite markers to explore population change. Previous fine-scale analysis of UK harbour seal populations revealed three clusters in the UK, with a northeastern cluster that included our Moray Firth study population. Our analysis revealed that the Moray Firth cluster is an independent genetic group, with similar levels of genetic diversity across each of the localities sampled. These samples were used to assess historic abundance and demographic events in the Moray Firth population. Estimates of current genetic diversity and effective population size were low, but the results indicated that this population has remained at broadly similar levels following the population bottleneck that occurred after post-glacial recolonization of the area. 


\title{
Evolutionary history of a Scottish harbour seal population
}

Natacha Nikolic ${ }^{1,2}$, Paul Thompson ${ }^{3}$, Mark de Bruyn ${ }^{4}$, Matthias Macé5, Claude Chevalet ${ }^{2}$

(1) ARBRE (Reunion Island Biodiversity Research Agency), Saint-Leu, La Réunion, France

(2) Génétique Physiologie et Systèmes d'Elevage - UMR1388, INRAE, Castanet-Tolosan, France.

(3) Lighthouse Field Station, School of Biological Sciences, University of Aberdeen, Cromarty, U.K

(4) School of Life and Environmental Sciences, University of Sydney, Sydney, Australia

(5) Laboratoire d'Anthropologie Moléculaire et d'Imagerie de Synthèse - UMR 5288, CNRS, Université de Toulouse, Université Paul Sabatier, Toulouse, France

\begin{abstract}
Efforts to conserve marine mammals are often constrained by uncertainty over their population history. Here, we examine the evolutionary history of a harbour seal (Phoca vitulina) population in the Moray Firth, northeast Scotland using genetic tools and microsatellite markers to explore population change. Previous fine-scale analysis of UK harbour seal populations revealed three clusters in the UK, with a northeastern cluster that included our Moray Firth study population. Our analysis revealed that the Moray Firth cluster is an independent genetic group, with similar levels of genetic diversity across each of the localities sampled. These samples were used to assess historic abundance and demographic events in the Moray Firth population. Estimates of current genetic diversity and effective population size were low, but the results indicated that this population has remained at broadly similar levels following the population bottleneck that occurred after post-glacial recolonization of the area.

Running title:

Evolutionary history of harbour seal

Keywords:

Evolution, genetic, seal

Corresponding author:

Natacha Nikolic

ARBRE (Agence de Recherche pour la Biodiversité à La Réunion), 18 rue des Seychelles, 97436

Saint-Leu, La Réunion.Email address: natachanikolic@hotmail.com
\end{abstract}


73

\section{Introduction}

Efforts to conserve marine animals are frequently constrained by uncertainty over historic baselines and the factors driving changes in abundance (Lotzke and Worm 2009). A variety of techniques have been developed to address this issue, including archaeological investigations (Rick and Lockwood 2012), studies based upon historical records or traditional knowledge (McClenachan et al. 2012), and molecular analyses of changes in genetic diversity (Roman and Palumbi 2003; Palsboll et al. 2012).

Harbour seals (Phoca vitulina) are widely distributed around the North Atlantic and North Pacific coasts, but studies over recent decades have identified wide variations in the status of these populations. Abundance in many parts of Europe was severely reduced by successive outbreaks of Phocine Distemper Virus (PDV), but mortality in some populations was low (Heide-Jørgensen et al. 1992; Härkönen et al. 2006). Similarly, longer-term trends in harbour seal abundance show steady increases in some parts of their range (Jeffries et al. 2003; Aarts et al. 2019), whereas other regions have experienced unexplained declines (Boveng et al. 2003; Lonergan et al. 2007; Hanson et al. 2017; Thompson et al. 2019).

These changes have resulted in new conservation measures in many areas, the most significant of which in European waters is the EU Habitats Directive (Baxter 2001). This requires EU Member States to develop a NATURA 2000 network of Special Areas of Conservation (SACs) for a range of key species, including harbour seals (Thompson et al. 2019). In UK waters, SACs have been established within eleven management units that reflect the current understanding of genetic structure (Olsen et al. 2017), but there is uncertainty over the causes underlying different regional trends in abundance and historic baselines (Mathiopoulos et al. 2014; Thompson et al. 2019). Here, we focus on the evolutionary history of a population that uses one of these SACs, in the Moray Firth, NE Scotland. In this area, individual-based studies since 2006 have provided detailed estimates of contemporary vital rates (Cordes and Thompson 2014; Mathiopoulos et al. 2014) during a period where there has been no clear trend in abundance (Thompson et al. 2019). The most recent counts indicate that the population has declined by around 40\% since the mid 1990's (Thompson et al. 2019), but direct information on the historic abundance and evolution over multiple generations is lacking given the lack of comparable survey data prior to this. An alternative approach is to assess historic changes in the genetic-based indicator, effective population size $(\mathrm{Ne})$. The effective size reflects the abundance and evolutionary history of the population, and can inform conservation efforts because it affects the degree to which a population can respond to selection (Berthier et al. 2002).

Analysis of neutral molecular markers such as microsatellites can be used to calculate $N e$ and provide an evolutionary perspective to these conservation and management issues (King et al. 2001). Genetic studies conducted on harbour seals have generally used less than 15 microsatellite markers for "Atlantic" harbour seals (12 in Olsen et al. (2017); 15 in Andersen et al. (2011); 7 in Goodman (1997, 1998)) and less than 20 for "Pacific" harbour seals (5 in Burg et al. (1999), 8 in Curtis et al. (2011), 7 in Dishman (2011), 20 in Hayes et al. (2006) and 6 in Herreman (2009)). We used the markers developed specifically for harbour seal microsatellites (Allen et al. 1995; Coltman et al. 1996; Goodman 1997) and a mix of pinniped microsatellite markers (Allen et al. 1995; Buchanan et al. 1998; Davis et al. 2002; Gelatt et al. 2001), as other harbour seal 
83 microsatellite papers (ex. Olsen et al. 2017). We therefore tested 30 markers, which allowed us to 84 utilise 17 polymorphic microsatellite markers (25 markers minus 8 monomorphic markers) for 85 genetic analysis of harbour seals. Previous studies of genetic structuring of UK harbour seals 86 (Goodman 1996; Olsen et al. 2017) suggest that there are two main groups consisting of localities 87 in the northern UK, and the southern UK and mainland Europe (Olsen et al. 2017). However, 88 Olsen et al. (2017) further divided these groups into geographically distinct genetic clusters, 89 including the North-East England and Eastern Scotland cluster (cf. Figure 1 of Hanson et al. 2017) 90 that includes our Moray Firth study sites. Here, we extended the number of microsatellite markers available for harbour seals in the Moray Firth to estimate historic changes in effective population size in this region.

Using this extended set of microsatellite markers, the objectives of the present study were to address the following questions: (i) what does current genetic diversity tell us about historic changes of harbour seal effective population sizes?, and (ii) how might genetic data contribute to understanding the decline of seals in the north-east of Scotland?

\section{Material \& Methods}

\section{Study area}

The Moray Firth study population (Figure 1) contained an estimated 1,653 harbour seals in 1993 (Thompson et al. 1997a) when the samples used in this study were collected. Seals come ashore at inter-tidal sites throughout the year, with most pups born in three sub-areas spaced approximately $50 \mathrm{~km}$ apart (Dornoch Firth, Cromarty Firth, and Beauly Firth). One of these subareas, in the Dornoch Firth, has been designated as a SAC to protect harbour seal populations under the EU Habitats Directive (Cordes et al. 2011; Thompson et al. 2019).

\section{(Figure 1)}

\section{Samples and DNA extraction}

Archived blood samples were collected from 93 harbour seals that had been captured, sampled and released as part of earlier ecological studies (Thompson et al. 1997b; Hall et al. 2019). Samples were collected between 1992 and 1995 (see Thompson et al. 1997b for details of capture and sampling methods), and constituted 47 females and 46 males (48 juveniles, 37 adults, 8 sub-adults, data are available at https://doi.org/10.15454/AOZ7JI); representing approximately $6 \%$ of the population. All capture and handling methods were carried out in accordance with the approved guidelines and conducted under licences from the UK Home Office. Blood samples were collected under Home Office licence issued to the University of Aberdeen under the Animal (Scientific Procedures) Act 1986 (PPL number 60/01351). These samples were preserved at $-20^{\circ} \mathrm{C}$ and hydrated with PBS (Phosphate Buffered Saline) before DNA extraction. Genomic DNA was extracted by QIAamp DNA Blood Mini Kit (QIAGEN) (see the supplementary text - S1 for more details).

\section{Marker selection and genotyping}


129 Because the number of available harbour seal microsatellite markers was low, we considered all

130

131

132

133

134

135

136

137

138

139

140

141

142

143

144

145

146

147

148

149

150

151

152

153

154

155

156

157

158

159

160

161

162

163

164

165

166

167

168

169

170

171

172

173

174 potential microsatellites for this species and additionally from other pinnipeds - Halichoerus grypus, Hydrurga leptonyx (two species belonging to the family Phocidae) and Odobenus rosmarus rosmarus (Odobenidae). A total of 30 markers were tested (Appendix A). Previously some primers were designed using Primer 3 (Rozen and Skaletsky 2000) because only the amplified sequences were provided by the authors (ie the primers H12, HL20, HL16, HL15) (Appendix B). The primers PVC63 were redefined using Primer 3 to optimize amplification. We retained 25 loci that amplified reliably (meaning that on 12 individuals tested a minimum of 10 were successfully amplified and visualized on agarose gel) for harbour seals (Appendix B), with a minimum of twelve repeat motifs and a GC percentage of approximately $50 \%$.

All 93 harbour seal samples were successfully genotyped with these 25 microsatellite markers using fluorescent labelled primers and multiplex PCR pools (Appendix A, B). PCR amplification was carried out using an Applied Biosystems 2720 Thermal Cycler with $10 \mu$ reaction volume containing $~ 50 \mathrm{ng}$ DNA, $1.5 \mathrm{mM} \mathrm{MgCl}_{2}$, 1x Promega buffer, $200 \mu \mathrm{M}$ dNTPs, $0.5 \mu \mathrm{M}$ each primer, $0.5 \mathrm{U}$ Taq DNA polymerase (Promega). An initial denaturation step at $94{ }^{\circ} \mathrm{C}$ for 5 min was followed by $42-45$ cycles of $30 \mathrm{~s}$ at $94{ }^{\circ} \mathrm{C}, 30 \mathrm{~s}$ at $\mathrm{Tm}^{\circ} \mathrm{C}$ (annealing temperature), $30 \mathrm{~s}$ at $72{ }^{\circ} \mathrm{C}$, followed by a final elongation step of $30 \mathrm{~min}$ at $72{ }^{\circ} \mathrm{C}$. The annealing temperatures were optimised for each locus (Appendix B). The PCR products $(2 \mu \mathrm{l})$ were added to a mixture of deionised formamide and the internal size standard GENESCAN-400HD Rox (Applied Biosystems) ( $8 \mu \mathrm{l})$, then denatured for $5 \mathrm{~min}$ at $95{ }^{\circ} \mathrm{C}$. For this mixture (formamide and internal size standard), we prepared a final volume of $1000 \mu \mathrm{l}$ with $982.5 \mu \mathrm{l}$ of formamide and 17.5 $\mu$ l GENESCAN-400HD Rox. Individual electropherograms were obtained using an ABI 3730 multi-capillary sequencer. PCR products were visualised by GeneMapper v4.0 software (Applied Biosystems) (see the data and profile examples per pool at https://doi.org/10.15454/AOZ7JI). Across the panel of 25 markers, 8 were monomorphic (Appendix B) in both male and female individuals. The genetic analysis was performed on the overall panel (25 markers) and on the polymorphic markers (17 markers).

\section{Analysis of diversity and genetic differentiation}

To ensure that the number of loci was sufficient, we calculated the probability of individual identity (PI; the probability that two individuals in a population have identical genotypes) for each locus and their combinations with the program GENALEX (Peakall and Smouse 2006, 2012). SPOTG (Hoban et al. 2013) was used to estimate the power of individual assignment, using 1,000 runs, the number of sampled individuals (93), the mean number of alleles (4), and the FST values found in this study under a normal allele frequencies model.

Genetic diversity was measured as the mean number of alleles per locus (A) for 25 markers. Excluding the monomorphic markers we measured observed heterozygosity $(\mathrm{Ho})$, expected heterozygosity $(\mathrm{He})$, and Nei's (1978) unbiased heterozygosity (H.n.b) using GENETIX 4.05.2 (Belkhir et al. 1998). Estimates of homozygote and heterozygote excess that differed significantly from zero $(\mathrm{p}<0.05)$ were calculated from the standard error rates with confidence intervals in Pedant (Johnson and Haydon 2007). Deviations from Hardy-Weinberg Equilibrium (HWE) were assessed using polymorphic loci, and exact tests with p-values and their standard errors were computed using ARLEQUIN version 3.1 (Excoffier et al. 2005; Excoffier and Lischer 2010) with 
175 permutations (1,000,000 chains and 100,000 steps). Polymorphism information content (PIC) was 176 generated in Cervus (Kalinowski et al. 2007). Probability of parentage exclusion (PE1, single 177 parent (Jamieson and Taylor 1997); PE2, a second parent given a first parent assigned (Jamieson 178 1994); PE3, a pair of parents (Jamieson and Taylor 1997)) was estimated per locus using INEst 179 (Chybicki and Burczyk 2009). The potential occurrence of null alleles and scoring errors due to 180 stuttering or large allele dropout in the data set was assessed using the software MICRO181 CHECKER (Oosterhout et al. 2004), and the significance of null allele frequency (Fnull) was 182 estimated with INEst using the individual inbreeding model with 100,000 iterations (estimates 183 significantly different from zero, $\mathrm{p}<0.05$ ). The inbreeding coefficient FIS was estimated from 184 polymorphic loci with 10,000 bootstraps by GENETIX software. FIS measures the decrease in 185 heterozygosity due to inbreeding, assortative mating, or selection. Genotyping error rate per allele, 186 E1 referring to allelic dropout rate and E2 to the false allele rate, and the $95 \%$ confidence interval 187 (CI) with 10,000 permutations, were evaluated with maximum likehihood from 10 individuals' 188 random replicates by marker based on He computed in Pedant. The number of repeated genotypes 189 (Nrep) and the percentage (\%) of the total number of individuals genotyped for each loci were also estimated.

Our findings were consistent with the previous study identifying Moray Firth sites as part of one genetic cluster (Olsen et al. 2017). Thus, we also investigated whether external migrations (e.g. gene flow from another cluster) were possible because grouping several different populations could skew our analyses of evolutionary history. Genetic differentiation was visualized by Factorial Correspondence Analysis $(F C A)$ in GENETIX using the polymorphic loci $(\mathrm{n}=17)$. Pairwise Wright's F-statistics FST (Weir and Cockerham 1984) and their levels of significance were assessed based on 10,000 permutations using ARLEQUIN 3.1 (Excoffier et al. 2005), considering geographical location per individual. Number of migrants $(\mathrm{Nm})$ was estimated through the frequency of private alleles with GENEPOP (Raymond and Rousset 1995; Rousset 2008)

201

202

203

204

205

206

207

208

209

210

211

212

213

214

215

216

217

218

219

220 online (http://genepop.curtin.edu.au). We estimated only the level of migration rates $(m)$ (superior or inferior to 0.1 , and not the values of gene flow due to uncertainty with a weak genetic structure) using the Bayesian multi-locus genotyping approach implemented in BAYESASS 3.0.4 (Wilson and Rannala 2003) with different random number seed values (S) and sampling frequency (n), $10,000,000$ iterations, and a burn-in period of 1,000,000. To detect immigration into the Moray Firth, we used Rannala and Mountain's (1997) estimate and ran Monte-Carlo simulations with 10,000 repetitions implemented in GENECLASS2 software (Piry 2004), considering geographical location per individual.

Finally, we used a population assignment test to check for sex-biased dispersal using the software GENALEX. This method produces an Assignment Index correction (AIc) for each sex following the method of Mossman and Waser (1999). Negative AIc values characterize individuals with a higher probability of being migrants (high dispersion) and positive values characterize individuals with a lower probability of being migrants. Mean AIc values were compared for each sex with a non-parametric Mann-Whitney U-test using R version 3.0.2 software. Moreover, hierarchical Analysis of Molecular Variance (AMOVA) analyses were performed, with 9,999 permutations, for each sex on their own, and for the combined male and female data set to determine whether genetic variation was similar for males and females.

\section{Clustering analysis}


221

222

223

224

225

226

227

228

229

230

231

232

233

234

235

236

237

238

239

240

241

242

243

244

245

246

247

248

249

250

251

252

253

254

255

256

257

258

259

260

261

262

263

264

265

266

STRUCTURE 2.3 (Pritchard et al. 2000) was used to identify population structure and individual admixture coefficients. Five independent runs were performed on STRUCTURE for each assumed number of population(s) $K=1-6$ under an admixture model. All runs were executed with 50,000 burn-in periods and 200,000 MCMC (Markov chain Monte Carlo) repetitions, using the three regions defined earlier as prior information. STRUCTURE HARVESTER 0.6.94 (Earl and vonHoldt 2012) was used to visualise results and assess $K$, the number of genetic populations that best fit the data, based on Maximum Likelihood (Evanno et al. 2005). Structure Selector (http://lmme.qdio.ac.cn/StructureSelector/) was also used to process the Puechmaille (2016) approach on uneven sampling and to also estimate the best $K$. Plots for optimal $K$ was performed with CLUMPAK (Kopelman et al. 2015).

In addition, a discriminant analysis of principal components (DAPC, Jombart et al. 2010) was performed using R package ADEGENET (Jombart 2008; Jombart and Ahmed 2011). DAPC is a multivariate analysis that integrates principal component analysis (PCA) with discriminant analysis to summarize genetic differentiation between groups (Jombart 2008). Sampling location was used as prior. While STRUCTURE forms genetic clusters of individuals by minimizing departure from Hardy-Weinberg and linkage disequilibria, DAPC maximizes genetic separation among groups and minimizes variation within groups (Jombart et al. 2010) which may constitute a more accurate approach for species exhibiting potentially high gene flow (Bailleul et al. 2018).

Isolation by distance was tested using a Mantel test between genetic (Euclidean Edwards' distance) and geographic distances with 10,000 resamplings between individuals and regions using ADEGENET, ADE4 (Thioulouse et al. 1997) and GRDEVICES (R Development Core Team and contributors worldwide) $\mathrm{R}$ packages.

\section{Effective population sizes and evolutionary history}

The average mutation rate on the set of loci $(\mu)$, ancestral time $(T f)$, and present and ancestral effective size ( $N o$ and $\mathrm{Na}$ ) were estimated for the seals using MSVAR (Beaumont 1999), running 80,000 MCMC chains and 20,000 iterations between chains. This method is suited to microsatellite data that are assumed to be evolving by a stepwise mutation model (SMM), sampled from a population that has varied in size. When compared with other classic coalescence models (TM3 and DIYABC) aimed at estimating the present and ancestral effective sizes, MSVAR was most efficient for small populations (Nikolic et al. 2009). Because we used this model only to get preliminary results for the seal mutation rate, and computation times are very long (here more than 3 days), this analysis was run only with the polymorphic panel (17 markers). MSVAR estimates the effective population size for the present and ancestral effective sizes but does not infer fluctuation of effective size between them. We applied Gelman and Rubin's (1992) test to monitor convergence of MCMC output.

To check for historic population declines in the seals, we used BOTTLENECK software (Piry et al. 1999) with 10,000 iterations and we applied three tests - the sign test, the standardized differences test (Cornuet and Luikart 1997), and the Wilcoxon sign-rank test (Luikart et al. 1997) to analyze the presence of heterozygote excess resulting from perturbation of allele frequencies. We applied the Wilcoxon signed-rank test specifically as it does not require a large number of

PeerJ reviewing PDF | (2019:12:44224:1:2:NEW 14 Apr 2020) 
267 polymorphic loci which are scarce in a population with low variability (Han et al. 2010). Inferences 268 from heterozygosity excess or deficiency tests are heavily influenced by the mutational model 269 (Busch et al. 2007). Here, we used the Stepwise Mutation model as it is thought to be a more

270

271

272

273

274

275

276

277

278

279

280

281

282

283

284

285

286

287

288

289

290

291

292

293

294

295

296

297

298

299

300

301

302

303

304

305

306

307

308

309

310

311

312

appropriate model for use with microsatellites (Nikolic and Chevalet 2014b).

Bayesian methods using coalescence theory and MCMC sampling to estimate posterior distributions of demographic parameters and history, seem more robust to certain violations of mutation model assumptions (Girod et al. 2011) and bottleneck duration (Peery et al. 2012). Hence, to estimate historic fluctuations of effective population size from microsatellite markers, we used the algorithm and method VarEff (Chevalet and Nikolic 2010; Nikolic and Chevalet 2014b) programming in $\mathrm{R}$ package. The model assumes a stepwise mutation model for microsatellites and makes use of an approximate likelihood of data based on theoretical results. It is then implemented in a MCMC framework which simulates past demography by sampling step functions. The model is freely available as an $\mathrm{R}$ package (https://forgedga.jouy.inra.fr/projects/package-vareff-variation-of-effective-population-size/). Results were based on MCMC chains including 10,000 dememorization steps, a total length of 1,000,000 and the extraction of 10,000 uncorrelated states as suggested by previous analysis (Nikolic and Chevalet 2014b). Results are provided in normalized scales $\hat{\theta}=4 \hat{N} \mu$ for population size (4* effective size*mutation rate) and $T=g \mu$ for time (number of generations *mutation rate), or in the natural scale, effective size $\mathrm{Ne}$ and generation number $g$ provided the mutation rate $\mu$ is known. For harbour seals, we set $\mu=0.00015$ and used the generation time of 8.75 years based upon the value used in Swart et al. (1996).

VarEff offers several functions to characterize the posterior distribution of effective size at several times in the past: arithmetic and harmonic means, median and mode of the distribution, detailed distribution at specified times, with the quantiles and standard deviation. In addition, the results of VarEff allow the posterior distribution of the Time to the Most Recent Common Ancestor (TMRCA) of two random alleles to be recovered, which provides complementary information on the occurrence and time of past bottlenecks, since peaks in this distribution indicate times when coalescence events likely occurred, and intervals between peaks may indicate periods when bottlenecks occurred. Depending on the intensity and shape of the peak and the value of effective size (obtained with the previous functions), information on the bottleneck event(s) can be recovered. Futhermore, because migration can mimic the effects of bottlenecks (Nikolic and Chevalet 2014b), we repeated the same analysis discarding the immigrants that were detected (2 individuals).

\section{Results}

\section{Genetic polymorphism and panel of markers}

Of the 25 microsatellite loci, eight loci were monomorphic for both sexes (PVC63, PVC74, $S G P V 3, P V C 26, P V C 29, G S 1, H l-16$, and OrrFCB23) and one marker $\mathrm{Hl}-20$ was monomorphic in males (Appendix B). These markers were hence excluded from the analyses resulting in a final panel of 17 polymorphic markers (Table 1). Our final genotyping data contained only 3.2\% missing data for 93 individuals and 17 polymorphic markers.

PeerJ reviewing PDF | (2019:12:44224:1:2:NEW 14 Apr 2020) 
313 The probability of identity (PI) values ranged from 0.023 to 0.927 and the probability of exclusion 314 (E1, E2, E3) from 0.001 to 0.921 (Table 1). A total of 9 markers had a probability of identity in 315 the higher range at 0.5 (Table 1). The analysis based on the cumulated probability of individual 316 identity (PI), an indication of the statistical power of marker loci, revealed that 10 to 17 317 polymorphic markers were sufficient to carry out the population genetics analysis of harbour seals 318 in the Moray Firth (Figure 2). SPOTG estimated that 93 individuals and 17 microsatellite markers 319 could detect power of individual assignment $>57 \%$ and connectivity $>87 \%$. However, the 320 theoretical study by Nikolic and Chevalet (2014) shows that the number of markers to assess

321

322

323

324

325

326

327

328

329

330

331

332

333

334

335

336

337

338

339

340

341

342

343

344

345

346

347

348

349

350

351

352

353

354

355

356

357

358

\section{(Figure 2)}

The total number of alleles for the remaining 17 loci ranged between 2 and 14 (Table 1), while the mean number of alleles was 3.7 (Table 1). The global mean of observed heterozygosity was 0.384 for the 17 polymorphic microsatellites. Estimates of homozygote and heterozygote excess were not significant except OrrFCB24 with a heterozygote excess (Table 1).

\section{(Table 1)}

Genotyping error rates and associated $95 \%$ confidence intervals were very close to zero for all loci HL20 and OrrFCB1 (Table 1). Most loci were close to HW equilibrium (P $>0.05$, Bonferroni correction applied) (Table 1) except SGPV11, SGPV17, PVC78 and OrrFCB24 (Table 1). The locus $S G P V 17$ has been suspected to be X-linked in pinniped species (Coltman et al. 1996; Gemmell et al. 1997; Pastor et al. 2004), although this remains equivocal (Herreman et al. 2008). Such a linkage would imply that males are homozygous for this marker. In the present study, we identified 3 alleles $(153,155$ and 161) at $S G P V 17$ with similar allelic frequencies in males and females. Heterozygote frequencies were 14/46 in males and 24/47 in females suggesting no Xlinkage for this locus. Analysis of sex-biased dispersal using the marker SGPV17 showed there were no significant differences in the mean AIc with the polymorphic panel (Mann-Whitney Utest, $\mathrm{p}$-value $=0.78$ ). This result indicates no sex-biased dispersal. Thus, we concluded that we have no reason to exclude the marker SGPV17 in the polymorphic panel on the basis of linkage.

MICROCHECKER estimated that only SGPV11 showed evidence for a null allele but the test by permutations with INest revealed that the result was not significant (Table 1). Null allele analyses were not significant for all loci (Table 1). Hence, there was no evidence for scoring error due to stuttering and no evidence of large allele dropout. The harbour seal population appears to be in Hardy Weinberg equilibrium with the global test $(\mathrm{P}=0.519)$.

With respect to the distribution of repeat numbers (Appendix C), harbour seals in the Moray Firth exhibited quite large distances between microsatellite alleles (up to 37 repeat numbers) and a large range of missing values (between 10 and 24, and between 26 and 36) that may be the signature of bottleneck events.

Genetic differentiation and clustering analysis 
Analysis of sex-biased dispersal (Mossman and Waser, 1999) ) showed no significant differences

361

362

363

364

365

366

367

368

369

370

371

372

373

374

375

376

377

378

379

380

381

382

383

384

385

386

387

388

389

390

391

392

393

394

395

396

397

398

399

400

401

402

403

in the mean AIc with the polymorphic panel (Mann-Whitney U-test, p-value $=0.69$ ), indicating no sex-biased dispersal. Futhermore, when males and females were considered separately in AMOVA analyses, no genetic differentiation was found between the sexes for the panel of polymorphic markers.

FIS values by permutations (sampling with replacement of individuals with all loci) were negative -0.081 (with CI narrow and negative, -0.129 and -0.044 ) and by Jacknife result on locus -0.079 (variance $=0.006$ ). Negative FIS values indicate that there were more heterozygotes than expected and individuals in the population may be less related than expected under a model of random mating. Global frequency distribution of observed and permuted $F S T$ values were not significant, as they lie well inside the distribution of FST for the null hypothesis. FSTs were $<0.05$ between the three geographic areas with only the value between Dornoch and Inverness $(0.014)$ being significant according to permutation tests (Appendix D). Corrected average pairwise differences were low and not significant (Appendix D). These values indicate an absence of significant differentiation. Clustering analyses (STRUCTURE and DAPC) supported the existence of one main cluster with no spatial differentiation and an absence of structuring between sampling localities (Appendix E) and sex. Moreover, the isolation by distance (Mantel test) was clearly not significant $(\mathrm{p}$-value $=0.12)$.

Concerning migration, FCA on individuals identified 4 axes with eigenvalues of 0.15 (axis 1), 0.089 (axis 2), 0.078 (axis 3), and 0.072 (axis 4). The three dimensional FCA (Appendix F) revealed two migrants as immigrants (one female from Cromarty and one male from Inverness), i.e. a rate of $2.15 \%$. The mean $\mathrm{Nm}$ value using private alleles, after correction for size, and considering the individual geographic localisation was $\mathrm{Nm}=4.52$. According to Wright (1969), $\mathrm{Nm}<1$ indicates strong genetic differentiation, and $\mathrm{Nm}$ much larger than 1 means that panmixia can be assumed for the localities of the population. Based on Hastings (1993), Faubet et al. (2007) suggest that $m<0.1$ is needed to ensure demographic independence of populations. In this study, $m$ were higher than 0.1 between sampling localisations in the Moray Firth.

Thus, the genetic differentiation and clustering analysis indicate that the harbour seal populations in the Moray Firth behave as a single genetic group. When considering the Moray Firth as a single genetic group, mean frequency of private alleles was equal to 0.03 which is consistent with the two immigrants detected by FCA. The Bayesian method of Rannala and Mountain (1997) did not detect immigrants into the Moray Firth. However, based on frequencies of Paetkau et al. (1995) and 10,000 resamplings, 5 of the 93 individuals were detected as immigrants (4 males and one female: 5\%). Nei's standard distance (1972) with 10,000 resamplings with the algorithm of Paetkau et al. (2004) showed 4 immigrant individuals ( 2 females and 2 males), equivalent to around $4 \%$. Hence, the global immigration rate in the Moray Firth is in the range of 2 to $4 \%$.

\section{Evolutionary trends}

Most markers shared a similar range of mutation rates of around 0.0001-0.0002 with MSVAR estimates. VarEff provided global estimates of $\hat{\theta}=4 \hat{N} u$, roughly corresponding to present $(\hat{\theta} \mathrm{o}=$

Peer) reviewing PDF | (2019:12:44224:1:2:NEW 14 Apr 2020) 
404 0.77), ancestral $(\hat{\theta} \mathrm{a}=38.90)$, and intermediate times $(\hat{\theta} \mathrm{I}=8.56)$ that help fix priors for effective 405 size.

406

407

408

409

410

411

412

413

414

415

416

417

418

419

420

421

422

423

424

425

426

427

428

429

430

431

432

433

434

435

436

437

438

439

440

441

442

443

444

445

446

447

448

The global estimates in the present effective sizes of VarEff provided results in the same order of magnitude as those from MSVAR for seals particularly in terms of median but with lower standard deviations ( $\mathrm{Sd}$ ) (Table 2).

(Table 2)

According to Gelman and Rubin's test (Gelman and Rubin 1992), convergence in the MSVAR estimations of the effective size occurred after 20,000 iterations; and run 4 was the best supported (Appendix G). The results from MSVAR suggested that the effective size of the Moray Firth harbour seal population during our study period (1990-1995) was 821-1,669 (No) (sd 2,979), and that the ancestral effective size was much higher around 128,000-340,000 $(\mathrm{Na})(\mathrm{sd} 846,836)($ Table 2 ). Values for mutation rates were around 0.0001-0.0002 $(\mu)(\mathrm{sd} 0.00026)$, and the ancestral coalescent time was estimated to occur 37,000-96,000 years ago (Tf) (sd 219,518) (Table 2).

VarEff harbour seal effective size priors were set between $\hat{N}$ o and $\hat{N} \mathrm{i}$ from the global current ( $\hat{\theta} \mathrm{o})$ and intermediate ( $\hat{\theta} \mathrm{i})$ theta $(4 \hat{N} u)$ estimates: the prior mean was set to $\hat{N}=5,000$ with a large variance (equal to 3 as suggested by Nikolic and Chevalet (2014a) for the logarithms of $N$ ). The estimate of present effective size (mean harmonic $(N o)$ and $\left.\hat{N}_{0}\right)$ was around 700 and 1,300 and the ancestral effective size $(\hat{N} a)$ 65,000 (Table 2). We also analysed females and males separately and obtained similar effective sizes which is consistent with no sex-biased dispersal. The arithmetic mean, harmonic mean, mode, and median of the posterior distributions for effective population sizes of harbour seals revealed a trend pattern that looks similar with a recent decrease from a higher effective size (Figure 3A). A decrease in effective size of around $2.5 \%$ was suggested during the last 25 generations. The effective size at generation $0(\mathrm{No})$ was 649 for the harmonic mean, 988 for the arithmetic mean, 714 for the median and 729 for the mode. This represents a 388-2,181 $95 \%$ confidence interval. The difference observed between estimators of past $\mathrm{Ne}$ (mean, median and mode) (Figure 3A) is likely to be due to the long tail of the posterior probability distribution (Nikolic and Chevalet 2014a).

\section{(Figure 3)}

According to global estimates ( $\hat{\theta} \mathrm{o}, \hat{\theta} \mathrm{i}, \hat{\theta} \mathrm{a})$ and effective size distribution (Figure 3 ) from VarEff, harbour seals in the Moray Firth came from a large ancestral population. The estimated effective sizes in the past suggest that the extant population derived from an ancestral population of around 10,000-15,000 individuals approximately 5,000-30,000 generations ago (Figure 3 ). This seems to be preceded by a lower ancient size (around 2,000-3,000 individuals) some 30,000-100,000 generations ago (Figure 3C); however this should be considered with caution, given the flat posterior distribution in ancient times. Concerning the recent and historical effective size, several decreases of the effective size were observed. Firstly, a long period of decline over the last 2,000 generations (17,500 years) was suggested (Figure 3A,B), when population size decreased from tens of thousands to less than 1,000 (Figure 3A, Figure 4A) and followed by a further decline prior to 600 generations ago (Figure 4), estimated at around 800 generations ago (Figure 5). Finally, a 
449

450

451

452

453

454

455

456

457

458

459

460

461

462

463

464

465

466

467

468

469

470

471

472

473

474

475

476

477

478

479

480

481

482

483

484

485

486

487

488

489

490

491

492

493

494 recent accelerated decline during the last 100 generations was followed by a period when population size remained approximately constant $(\mathrm{Ne}$ between $\approx 665$ and 685) (Figure 4).

\section{(Figure 4)}

The VarEff results describing the global evolution of the population are consistent with the tests of heterozygosity excess (sign, standardized and Wilcoxon tests) assuming SMM as proposed in BOTTLENECK (Appendix H). The latter analysis suggested a recent bottleneck in the northeastern UK population. Bayesian methods make use of coalescence theory and MCMC sampling to characterize demographic history and can have a higher probability of detecting bottlenecks than heterozygosity excess tests (contrasts heterozygosity expected under Hardy-Weinberg equilibrium with heterozygosity expected under mutation-drift equilibrium calculated from observed number of alleles) (Cornuet and Luikart 1997; Girod et al. 2011; Peery et al. 2012). Concerning the coalescent results from VarEff, Figure 4A represents the harmonic mean of the last 1,000 generations (A), which was characterized by a decrease followed by a slight increase before a further decrease in the last 100 generations. Variation over the last 1,500 years is also shown in Figure 4B, based upon the assumed generation time of 8.75 years.

\section{(Figure 5)}

According to Figure 5, which shows the distributions of TMRCA, the harbour seal population underwent drastic bottlenecks. The more recent times of the bottlenecks were estimated in generation time $(\mathrm{G})$ and in years, assuming a generation time of 8.75 years. Figure 5 also reveals that huge coalescence events occurred between 7,000-10,000 years (around the first peak in Figure 5). These coalescence events occurred after a period of decline of the population size (the drastic bottleneck seen around 17,000 years ago, the time when the density is at a minimum between the two peaks). Before that period, coalescence events occurred at times given by the second peak of the distribution, which corresponds to the large ancestral population size, as illustrated in Figures 3 and 4. Harbour seal showed declines over the last 1,000 years, with a steeper decline over the last few centuries. Futhermore, the analysis run without the two detected immigrants provided exactly the same results.

\section{Discussion}

\section{Genetic diversity}

Results from the PI and SPOTG simulations suggest that the number of individuals and polymorphic markers are sufficient to provide high assignment discrimination and to detect evolutionary and ecological processes. The low genetic diversity in Moray Firth harbour seals, with an overall average heterozygosity of $38 \%$ and 3.7 alleles per microsatellite locus, was lower than in many pinnipeds (summarised in Curtis et al. 2011). However, this value falls within the range recorded for other North Atlantic harbour seal populations, which were estimated between 24\% (Coltman et al. 1996), 38\% (Olsen et al. 2017) and 50\% (Goodman 1998). In contrast, higher levels of heterozygosity ( $>65 \%$ ) have been recorded in the North Pacific (Burg et al. 1999). There is concern that small populations with low genetic diversity may become susceptible to environmental, demographic, and genetic stochasticity, increasing their risks for extinction

PeerJ reviewing PDF | (2019:12:44224:1:2:NEW 14 Apr 2020) 
495 (Franklin 1980; Newman and Pilson 1997; Brook et al. 2002). However, low genetic diversity 496 appears to be common amongst many marine mammals (Hoelzel et al. 2002), and the conservation 497 implications of contemporary patterns are difficult to assess without some understanding of the 498 relative role of natural and anthropogenic influences on historic population sizes. For example, 499 low levels of genetic diversity may simply exist in some populations because of the nature of their 500 social structure (Whitehead 1990), or due to founder effects that occurred following natural post501 glacial habitat change (Palsbøll et al. 1997). It is likely to be of greater concern to managers where 502 low diversity has resulted from more recent over-exploitation (Hoelzel 1993) or bycatch (Pichler 503 and Baker 2000).

504

505

506

507

508

509

\section{Genetic structure}

Our data suggest that the Moray Firth acts as one genetic group, in accordance with the results of Olsen et al. (2017). Migration per generation above 5-10\% can strongly influence the estimate of effective size (Waples and England 2011) and it was therefore important to exclude this potential

510 bias by evaluating gene flow. Current gene flow of harbour seals into the Moray Firth was low 511 (immigration 2-4\%), likely because the adults are strongly philopatric (Thompson and Hall 1993; 512 Härkönen and Harding 2001). Goodman's (1998) study of European harbour seal population 513 differentiation suggests a critical range over which animals are philopatric of around $485 \mathrm{~km}$. In 514 that study, samples collected in the Moray Firth (Scottish east coast) were further than $500 \mathrm{~km}$ 515 from neighbouring genetic populations (Scottish west coast, Olsen et al. 2017). In a Neighbor516 joining phenogram presented in the Goodman study (1998), harbour seals from the Scottish east 517 coast were distinguable from the Scottish west coast with only 7 microsatellite loci, even though 518 the number of seals from the Scottish west coast was very low (18 individuals). In a recent genetic 519 clustering analysis with 12 microsatellite loci (Olsen et al. 2017), north-west and north-east UK 520 were considered two geographically distinct genetic clusters. The genetic homogeneity between

521

522

523

524

525

526

527

528

529

530

531

532

533

534

535

536

537

538

539

540 the Moray Firth and other north-eastern localities (Orkney and Shetland; Olsen et al. 2017), and associated low immigration, suggest that we can develop a robust reconstruction of evolutionary history for the north-eastern Scottish population.

\section{Effective population size (Ne)}

Inferring $N e$ from an estimate of $\theta$ can be obtained assuming a mutation rate. We estimated the mutation rate at around 0.0001-0.0002, similar to that found in ringed seals (Phoca hispida) (Palo et al. 2003), allowing us to estimate effective population size. Using the complete panel of polymorphic markers with and without immigrants identified by the assignment method, the effective size estimated by the coalescent tool (VarEff) at generation 0 (No) was around 500-1,000 (CI: 388-2181). The advantage of VarEff is that it can estimate the recent historic abundance from theta $(\hat{\theta} \mathrm{o})$ (average of the effective size on the last evolutionary stage) and the current abundance from $N o$ (effective size at generation time 0 ). $N e$ is a theoretical measure of an idealized population size that would be expected to experience the same rate of genetic diversity loss due to genetic drift (Wright 1931). Ne is hence defined as the size of an 'ideal' population with the observed rate of genetic drift (Wright 1931, 1969) and thus does not represent census population size (Palsbøll et al. 2013). In ecology, $N e$ is usually thought of as the number of breeding individuals that successfully transmit their genes to the next generation (Frankham 1995) and thus should equal the 'genetic' effective population size (Palsbøll et al. 2013). In practice, the exact relationship is

PeerJ reviewing PDF | (2019:12:44224:1:2:NEW 14 Apr 2020) 
541 rarely known and most studies apply a generic ratio representing a range of estimates (Palsbøll et 542 al. 2013). Small $N e$ with no or limited gene flow among populations tend to accelerate stochastic 543 loss of genetic diversity and can increase population risk as it leads to inbreeding depression and 544 reduced fertility, and increases the potential fixation of deleterious alleles (Fagan and Holmes 545 2006; Gilpin and Soulé 1986; Palstra and Ruzzante 2008; Lonsinger et al. 2018). Franklin (묘 546 suggested a minimum $\mathrm{Ne} \geq 50$ may be required to avoid short-term inbreeding depression, and an $547 N e \geq 500$ may be necessary to maintain long-term adaptive potential. However this rule (50/500) 548 is open to criticism as the estimates do not take into account the force of selection. According to 549 Lande (1995), wild populations could not bear the same consanguinity as farm populations (purged 550 by humans); wild populations would fall more quickly into inbreeding depression and therefore 551 the 50/500 rule would be underestimated. Lande (1995) recommended an $\mathrm{Ne}$ of 5,000 for long552 term viability. Other analyses (Allendorf and Ryman 2002) suggested an $\mathrm{Ne}$ of 1,000 to prevent 553

554

555

556

557

558

559

560

561

562

563

564

565

566

567

568

569

570

571

572

573

574

575

576

577

578

579

580

581

582

583

584

585

586 accumulation of harmfull mutations. All these recommended values must be taken with caution, as they ignore uncertainty arising from environmental and demographic factors, but they encourage conservation of small populations (Groves 2003).

$N e$ is typically smaller than census population size $(N)$ and this ratio may help for assessing the genetic health of a population and for predicting short-term and long-term risk (Palstra and Ruzzante 2008). This ratio varies from $10^{-5}$ in many marine invertebrate species to nearly 1.0 in some terrestrial vertebrates (Frankham 1995; Hedrick 2005), but comparative data for other pinnipeds are difficult to interpret due to the high level of uncertainty in census population size (Curtis 2011). Surveys during the sampling period resulted in a direct estimate ( $N$, census population size) of approximately 1,650 individuals (1993) for Moray Firth locality (Thompson et al. 1997a), 773 individuals in 1992 and 575 in 1994 for Firth of Tay and Eden Estuary (Hanson et al. 2015), 9,000 and 6,000 individuals in 1997 for north coast and Orkney, then Shetland respectively (Figure 4 from Duck and Morris 2015). These different values suggest that the ratio $N o / N$ can be very different depending on sampling location considered. The No estimate in this study represents one genetic cluster, the north-east UK, and including all $N$ would be unwise until we verify that $N o$ from other localities are in the same general estimate. Although $N$ is a relatively straightforward entity, it can be difficult to obtain (Palsbøll et al. 2013). Hence, in order to infer $N$ from $\mathrm{Ne}$, a rigorous estimate of the ratio is warranted (Palsbøll et al. 2013).

\section{Evolutionary trends}

Over $80 \%$ of UK harbour seals are found in Scotland and estimating the historic effective size of harbour seal in the Moray Firth showed that seals have recently experienced a decline, as also revealed by direct counts in parts of both the north-east Atlantic (Thompson et al. 2019; Lonergan et al. 2007; Hanson et al. 2017) and the north-west Atlantic (Bowen et al. 2003). Concerning the ancestral harbour seal population size (MRCA) in the Moray Firth, both models suggested that effective population size had once been extremely large; in the region of 65,000-130,000 derived from ancestral theta for VarEff and the median for MSVAR. One advantage of VarEff is the ability to infer demographic history from a single temporal sample, rather than depending on two or more samples that span multiple generations. Detecting past bottlenecks using the method relies on observing pairs of alleles that have coalesced during the bottleneck event (Nikolic and Chevalet 2014a). The VarEff method enables various mutation models to be considered, and some trials determined that the risk of false bottleneck detection due to an inappropriate mutation model would 
587 be unlikely. Results also indicated that the Moray Firth harbour seal population has undergone a 588 drastic bottleneck, which is concordant with the analysis of detection by the heterozygote 589 deficiency tests. Figures $3 \mathrm{~A}$ and B show that a recent strong bottleneck occurred approximately 5902,000 generations ago (17,500 years), when population size decreased from more than 10,000 to 591 less than 1,000 in about 1,000 generations. The model suggested an ancestral population size of 592 about 15,000 in ancient times, 30,000 generations or 262,000 years ago (the ultimate peak in the 593 TMRCA distribution, Figure 5). However, other evolutionary schemes could lead to a similar 594 distribution of TMRCA, such as recurrent immigration from a large population into the Moray 595 Firth. Thus, there are several possible interpretations for this pattern. The population may derive 596 from ancestral fragmentation followed by permanent introductions from a metapopulation made 597 of similar colonies, or it may be the result of a sharp decline some time in the past. Several 598 arguments support the bottleneck hypothesis: the gaps in the distribution of repeat numbers 599 (Appendix C), the rather low immigration rate, and the high probability that coalescent events 600 occurred recently. A more detailed answer will require archaelogical samples (ancient DNA) or 601

602

603

604

605

606

607

608

609

610

611

612

613 samples from a number of distant populations.

During the period corresponding to the drastic bottleneck detected, the current geographical range of this population would have been uninhabitable as it was covered by the last British Ice Sheet (Bradwell et al. 2008), and this ancestral population would likely have re-distributed to the margins of the ice sheet. Whilst the size of large terrestrial mammal populations in Europe is likely to have been reduced during this period (Marshall et al. 1982), harbour seals breed on ice in certain areas, and these colder conditions could have led to population expansion. For example, analysis of mtDNA variation in Antarctic ice-breeding seals indicated that effective population size expanded suddenly during times of intensified glaciations (Curtis et al. 2009), while southern elephant seals, which require access to open beaches, show the opposite trend (de Bruyn et al. 2009). The strong bottleneck detected at around 17,500 years ago appears to have occurred in the period following the retreat of ice from the current study area, as glacial moraines in the Inverness Firth indicate 614 that the ice margin occurred here around 15,000 years ago (Merritt et al. 1995). Subsequently, the 615 harbour seals may have recolonized this area once the ice retreated, as was the case for ringed seals 616 which colonized the Baltic Sea basin soon after deglaciation (11,500 years) (Palo et al. 2001).

617

618 The analysis of TMRCA revealed a peak of coalescence events around 800 generations $(7,000$ 619 years) ago in a period when mean effective size was approximately 5,000, and may correspond to a transient sharp decrease of effective size. This coincides with the warmest stages in the postglacial period in the mid-Holocene 8,000-7,000 years ago (Andersson 1902, 1909; Seppä et al. 2009). Current global distribution patterns indicate that harbour seals could have been restricted to more northerly waters at this time. Archaeological records also suggest that populations of harbour seals in the eastern Baltic were founded around 8,000 years ago (Härkönen et al. 2005), which may also reflect a northward shift in distribution during this period. Here, we see that this period may correspond to a transient decrease of the harbour seal population, long after it was derived from a larger ancestral population. Several dramatic events therefore appear to have influenced the structure and effective size of this population. This complexity inevitably brings uncertainty, particularly as the model cannot fully account for migration events.

630

631 Assuming immigration from a large external population, the distribution of coalescence time

632 TMRCA depends on the proportion $m$ of immigrants per generation and on the ratio $\varepsilon$ of the 
633 considered population size $(\mathrm{Ne})$ to the size of the larger external population (Nikolic and Chevalet 634 2014a). Using VarEff provides the distribution of TMRCA which is converted to past effective 635 sizes in an isolated population. In the case of small $4^{*} N e^{*} m$, such as found from the harbour seal 636 analysis, the estimated population size remains in the order of magnitude of the true $\mathrm{Ne}$ while 637 increasing with $m$ (Nikolic and Chevalet 2014a). However, for larger immigration rates from a 638 larger external population, a false current bottleneck could be predicted in a small population. 639 Applying the equation 8 of Nikolic and Chevalet (Nikolic and Chevalet 2014a), with hypothetical 640 immigration (2-4\%) from larger populations of harbour seals around the UK (Lonergan et al. 2007, 641 which brings $\varepsilon$ about 0.05 to 0.10 ) and specifically around our North-eastern Scottish population, 642 we estimated the time of a potentially false bottleneck at 100-200 generations ago. This period 643 matches with the last event detected in Figure 4. Thus, immigration from an external population 644 could potentially lead to a false current bottleneck (100-200 generations ago), and we have to be

649 Following the same analysis, the older bottlenecks detected at 800 and 2,000 generations ago cautious in the final decline in effective size observed (Figure 4). We encourage studies on seal migration in this area by the monitoring of individuals between the geographically distinct genetic clusters in UK and neighbouring waters. (Figure 3 and 5) should not be an effect of immigration. Either way, it is clear that these past events led to a decrease in population size resulting from natural environmental changes. This study suggests that, more recently, the harbour seal population has declined over the last century at a rate of $2-6 \%$ in terms of effective size. This downward trend could also result from natural changes in environmental conditions, or from human exploitation that is known to have occurred at many European and Arctic sites over the last millenia (Härkönen et al. 2005; Murray 2008).

\section{Conservation implications}

Previous population genetic studies of UK harbour seals have focused on using molecular tools to

660

661

662

663

664

665

666

667

668

669

670

671 support conservation management by identifying appropriate spatial management units (Olsen et al. 2017). Our study illustrates how genetic tools based on coalescent theory can also provide insights into evolutionary history and temporal changes in population size within those management units. Critically, they contribute knowledge about the state of a population by estimating changes in effective size. Estimates of the current effective population size of this harbour seal population are small compared to theoretical estimates of the minimum viable population size (Reed et al. 2003). Our analyses indicate that the harbour seal population in the north-east UK has remained at a broadly similar level following the bottleneck that occurred after post-glacial recolonization of the area but have slowly declined more recently. Subsequent demographic studies indicate that the Moray Firth population has declined further, by approximately 40\%, since the early 1990's when our DNA samples were collected (Thompson et al. 2019). Thus, whilst contemporary estimates of $N e$ are expected to remain well above the critical threshold of $N e=50$ suggested to avoid short-term effects of inbreeding (Franklin 1980) they will now be closer to the $\mathrm{Ne}=500$ potential threshold for maintainence of long-term adaptive potential(Franklin 1980). Molecular evidence of connectivity within the much larger European metapopulation exists (Olsen et al. 2017), but further work is required to better understand the extent to which contemporary movements between management units may offset these risks. Contrasting population trends in different UK management units (Thompson et al. 2019) also highlight the need for conservation managers to identify regional demographic drivers. Crucially, 
679 potential drivers include both anthropogenic stressors (which might require conservation 680 inerventions) and others such as competition with recovering grey seal populations (Halichoerus 681 grypus) (Wilson and Hammond 2019); where intervention is less likely to be appropriate. Previous 682 studies in the Baltic Sea indicate that populations of harbour and grey seal have co-varied over 683 historical time-scales (Harkonen et al. 2005). Our work illustrates how parallel coalescent studies 684 on material from sympatric grey and harbour seal populations in different regions now provides 685 an opportunity to inform conservation practices by exploring potential interactions between these 686

687

690 The authors wish to thank Shaneve Tripp (NYU School of Law) and Wendy West (DAFF) for 691 their english corrections. Ludovic Hoarau (IFREMER) for his help on ArcGis. Katia Feve 692 (INRAE) for her help with the DNA extraction protocol. DNA samples were extracted at INRAE 693 and genotyped at the Toulouse Genopole Platform (http://www.genotoul.fr/). Anonymous

\section{Author Contributions Statement}

Blood samples were collected on seals by the team of PT. NN, MM, and CC made the genotyping and genetic analysis. NN prepared the figures and tables. NN wrote the first version of the manuscript. All authors (NN, PT, MdB, MM, CC) revised and improved the manuscript. All authors (NN, PT, MdB, MM, CC) reviewed the manuscript.

\section{Additional Information}

Authors declare any competing financial interests in relation to the work described. Data are avalaible to the INRA dataset link https://doi.org/10.15454/AOZ7JI or https://data.inra.fr/dataset.xhtml?persistentId=doi:10.15454/AOZ7JI. 
709

710

711

712

713

714

715

716

717

718

719

720

721

722

723

724

725

726

727

728

729

730

731

732

733

734

735

736

737

738

739

740

741

742

743

744

745

746

747

748

749

750

751

752

753

\section{References}

Aguilar, A., Borrell, A., Reijnders, P. J. H. Geographical and temporal variation in levels of organochlorine contaminants in marine mammals. Mar. Environ. Res., 53, 425-452 (2002).

Allen, P. J., Amos, W., Pomedoy P. P., Twiss, S. D. Microsatellite variation in grey seals (Halichoerus grypus) shows evidence of genetic differentiation between two British breeding colonies. Mol. Ecol., 4, 653-662 (1995).Allendorf, F., Ryman, N. The role of genetics in population viability analysis. Population Viability Analysis / [ed] Beissinger,S.R. and McCullough, D.R., Chicago: University of Chicago Press , p. 50-85 (2002).

Andersen, L.W., Lydersen, C., Højholt Frie, A. K., Rosing-Asvid, A.. A population on the edge: genetic diversity and population structure of the world's northernmost harbour seals (Phoca vitulina). Bio. J. Linn. Soc., 102, 420-439 (2011).

Andersson, G. Hasseln i Sverige fordom och nu, Sveriges Geologiska Undersökning Serie Ca, 3 , $1-168$ (1902).

Andersson, G. The climate of Sweden in the Late-Quaternary period, Sveriges geologiska undersökning Serie Ca, 3, 1-88 (1909) .

Aarts, G., Brasseur, S., Poos, J.J., Schop, J., Kirkwood, R., van Kooten, T., Mul, E., Reijnders, P., Rijnsdorp, A. D., Tulp, I.. Top-down pressure on a coastal ecosystem by harbor seals. Ecosphere, 10:e02538 (2019).

Bailleul, D., Mackenzie, A., Sacchi, O., Poisson, F., Bierne, N., Arnaud-Haond, S. Large-scale genetic panmixia in the blue shark (Prionace glauca): A single worldwide population, or a genetic lag-time effect of the "grey zone" of differentiation?. Evol. Appl., 11(5), 614-630 (2018).

Baxter, J.M. Establishing management schemes on marine special areas of conservation in Scotland. Aquat. Conserv. Mar. Freshw. Ecosyst., 11, 261-265 (2001).

Beaumont, M. A. Detecting population expansion and decline using microsatellites. Genetics, 153, 2013-2029 (1999).

Belkhir, K. Borsa, P., Chikhi, L., Raufaste, N., Bonhomme, F. GENETIX, Logiciel sous Windows TM pour la Génétique des Populations. Laboratoire Génome et Populations, CNRS UPR 9060. Université de Montpellier II, Montpellier, France (1998).

Berthier, P., Beaumont, M.A., Cornuet, J-M., Luikart, G. Likelihood-based estimate of the effective population size using temporal changes in allele frequency: a genealogical approach. Genetics, 160, 741-751 (2002).

Bonner, W. Seals and man-a changing relationship. Bio. J. Linn. Soc., 38, 53-60 (1989).

Dietz, R., Heide-Jørgensen, M. P., Härkönen, T. Mass deaths of harbour seals (Phoca vitulina) in Europe. Ambio, 18, 258-264 (1989).

Boveng, P. L., Bengtson, J. L., Withrow, D. E., Cesarone, J. C. The abundance of harbor seals in the Gulf of Alaska. Mar. Mammal. Sci., 19, 111-127 (2003).

Bowen, W. D., Ellis, S. L., Iverson, S. J., Boness, D. J. Maternal and newborn life-history traits during periods of contrasting population trends, implications for explaining the decline of harbour seals (Phoca vitulina), on Sable Island. J. Zool., 261, 155-163 (2003).

Bradwell, T., Fabel, D., Stoker, M., Mathers, H., McHargue, L., Howe, J . Ice caps existed throughout the Lateglacial Interstadial in northern Scotland. J. Quaternary Sci., 23, 401-407 (2008).

Brook, B. W., Tonkyn, D., O'Grady, J. J., Frankham, R. Contribution of inbreeding to extinction risk in threatened species. Conserv. Ecol., 6(1), 16 (2002). 
754 Buchanan, F.C., Maiers, L.D., Thue, T.D., De March, B.G. Stewart, R.E. Microsatellites from the

755

756

757

758

759

760

761

762

763

764

765

766

767

768

769

770

771

772

773

774

775

776

777

778

779

780

781

782

783

784

785

786

787

788

789

790

791

792

793

794

795

796

797

798

799

Atlantic walrus Odobenus rosmarus rosmarus. Mol. Ecol., 7 (8), 1083-1085 (1998).

Burg, T. M., Trites, A. W., Smith, M. J. Mitochondrial and microsatellite DNA analyses of harbour seal population structure in the Northeast Pacific Ocean. Can. J. Zoolog., 77(6), 930-943 (1999).

Busch, J. D, Waser, P. M., DeWoody, J. A. Recent demographic bottlenecks are not accompanied by a genetic signature in banner-tailed kangaroo rats (Dipodomys spectabilis). Mol. Ecol., 16, 2450-2462 (2007).

Chevalet, C., Nikolic, N. Distribution of coalescent times and distances between microsatellite alleles with changing effective population size. Theor. Popul. Biol., 77(3), 152-163 (2010).

Chybicki, I. J., Burczyk, J. Simultaneous estimation of null alleles and inbreeding coefficients. $J$. Hered., 100, 106-113 (2009).

Coltman, D. W., Bowen, W. D., Wright, J. M. PCR primers for harbour seal (Phoca vitulina concolour) microsatellites amplify polymorphic loci in several pinniped species. Mol. Ecol., 5, 161-163 (1996).

Cordes, L.S., Duck, C.D., Mackey, B.L., Hall, A.J., Thompson, P.M. Long-term patterns in harbour seal site-use and the consequences for managing protected areas. Anim. Conserv., 14, 430438 (2011).

Cordes, L. S., Thompson, P. M. Mark-recapture modeling accounting for state uncertainty provides concurrent estimates of survival and fecundity in a protected harbor seal population. Mar. Mam. Sci. 30, 691-705 (2014).

Cornuet, J-M., Luikart, G. Description and power analysis of two tests for detecting recent population bottlenecks from allele frequency data. Genetics, 144, 2001-2014 (1997).

Curtis, C., Stewart, B. S., Karl, S. A. Pleistocene population expansions of Antarctic seals. Mol. Ecol., 18(10), 2112-2121 (2009).

Curtis, C., Stewart, B. S., Karl, S. A. Genetically effective population sizes of Antarctic seals estimated from nuclear genes. Conserv. Genet., 12, 1435-1446 (2011).

Davis, C. S., Gelatt, T. S., Siniff, D., Strobeck, C. Dinucleotide microsatellite markers from the Antarctic seals and their use in other pinnipeds. Mol. Ecol. Notes, 2, 203-208 (2002).

De Bruyn, M., Hall, B.L., Chauke, L.F., Baroni, C., Koch, P.L., Hoelzel, R.A.. Rapid response of a marine mammal species to Holocene climate and habitat change. Plos Genet., 5: e1000554 (2009).

Dishman, D. L. Genetic substructure of Pacific harbor seal (Phoca vitulina richardsi) populations along the coasts of Oregon and Washington. Dissertations and Theses (Open Access). Paper 312 (2011).

Duck CD, Morris CD. Surveys of harbour (common) and grey seals on the east, north and northwest coast of Scotland and in Orkney, including the Moray Firth and the Firth of Tay, in August 2013. Research report No. 759. Scottish Natural Heritage, (2014).

Earl Dent, A., vonHoldt Bridgett, M. STRUCTURE HARVESTER: a website and program for visualizing STRUCTURE output and implementing the Evanno method. Conservation Genetics Resources vol. 4 (2) pp. 359-361 doi: 10.1007/s12686-011-9548-7 (2012).

Excoffier, L., Laval G., Schneider, S. Arlequin ver. 3.0: An integrated software package for population genetics data analysis. Evol. Bioinform. Online, 1, 47-50 (2005).

Excoffier L, Lischer HEL. Arlequin suite ver 3.5: A new series of programs to perform population genetics analyses under Linux and Windows. Mol. Ecol. Resour., 10, 564-567 (2010).

Evanno G, Regnaut Sand Goudet J. Detecting the number of clusters of individuals using the software STRUCTURE: A simulation study. Mol. Ecol., 14, 2611-2620 (2005).

Peer] reviewing PDF | (2019:12:44224:1:2:NEW 14 Apr 2020) 
800 Fagan W. F., Holmes E. E. Quantifying the extinction vortex. Ecology Letters, 9(1), 51-60 (2006).

801 Faubet P, Waples R, Gaggiotti OE. Evaluating the performance of a multilocus Bayesian method 802 for the estimation of migration rates. Mol. Ecol., 16, 1149-1166 (2007).

803 Frankham, R. Effective population size/adult population size ratios in wildlife: a review. Genet. 804 Res., 66, 95-106 (1995).

805 Franklin, I. Evolutionary changes in small populations. In: Soule M, Wilcox B (eds) Conservation 806 biology: an evolutionary-ecological perspective. Sinauer Associates, Sunderland, 135-150 (1980). 807 Frankham, R. Effective population size adult population size ratios in wildlife-a review. 808 Genetical Research, 66, 95-107 (1995).

809 Gelatt, T.S., Davis, C.S., Siniff, D.B., Strobeck, C. Molecular evidence for twinning in Weddell 810 seals (Leptonychotes weddellii). J. Mammal., 82 (2), 491-499 (2001).

811 Gelman, A., Rubin, D. B. Inference from iterative simulation using multiple sequences, Stat. Sci., 812 7, 457-511 (1992).

813 Gemmell, N. J., Allen, P. J., Goodman, S. J., Reed, J. Z. Interspecific microsatellite markers for 814 the study of pinniped populations. Mol. Ecol., 6, 661-666 (1997).

815 Gilpin M. E., Soulé M. E. Minimum viable populations: Processes of species extinction In Soulé 816 M. E., editor. (Ed.), Conservation biology: The science of scarcity and diversity (pp. 19-34). 817 Sunderland, MA: Sinauer Associates (1986).

818 Girod, C., Vitalis, R., Lebois, R., Freville, H. Inferring population decline and expansion from 819 microsatellite data: a simulation-based evaluation of the MSvar methods. Genetics, 188, 165-179 820 (2011).

821 Goodman, S. J. Dinucleotide repeat polymorphisms at seven anonymous microsatellite loci cloned 822 from the European harbour seal (Phoca vitulina vitulina). Anim. Genet., 28(4), 310-311 (1997).

823 Goodman, S. J. Patterns of extensive genetic differentiation and variation among European 824 Harbour seals (Phoca vitulina vitulina) revealed using microsatellite DNA polymorphisms. Mol. 825 Biol. Evol., 15, 104-118 (1998).

826 Grove, C. Drafting a conservation blueprint: a practitioner's guide to planning for biodiversity. 827 University of Mishigan. p188. Island Press, (2003).

828 Hall, A. J., Mackey, B., Kershaw, J. L., Thompson, P. Age-length relationships in UK harbour 829 seals during a period of population decline. Aquatic Conserv: Mar Freshw Ecosyst. 29, 61- 70 830 (2019).

831 Han, J. B., Sun, F. Y., Gao, X-G., He, C-B., Wang, P-L., Ma, Z-Q., Wang Z-H. Low microsatellite 832 variation in spotted seal (Phoca largha) shows a decrease in population size in the Liaodong Gulf 833 colony. Ann. Zool. Fenn., 47, 15-27 (2010).

834 Hanson N, Thompson D, Duck C, Baxter J, Lonergan M. Harbour seal (Phoca vitulina) abundance 835 within the Firth of Tay and Eden estuary, Scotland: recent trends and extrapolation to extinction. 836 Aquat. Conserv., 27, 268-281, (2017).

837 Härkönen, T., Harding, K. C. Spatial structure of harbour seal populations and the implications 838 thereof. Canadian J. Zool., 79, 2115-2127 (2001).

839 Härkönen, T., Harding, K. C., Goodman, S. J., Johannesson, K. Colonization history of the Baltic 840 harbour seals: Integrating archaeological, behavioral and genetic data. Mar. Mammal. Sci., 21(4), 841 695-716 (2005).

842 Härkönen, T. Dietz, R., Reijnders, P., Teilmann, J. A review of the 1988 and 2002 phocine 843 distemper virus seal epidemics in European harbour seals. Dis. Aquat. Organ., 68, 115-130 (2006). 844 Hastings A. Complex interactions between dispersal and dynamics - lessons from coupled logistic 845 equations. Ecology, 74, 1362-1372 (1993). 
846 Hayes, S. A., Pearse, D. E., Costa, D. P., Harvey, J. T., Le Boeuf, B. J., Garza, J. C.. Mating system

847 and reproductive success in eastern Pacific harbour seals. Mol. Ecol., 15, 3023-3034 (2006).

848 Hedrick, P. Large variance in reproductive success and the $\mathrm{Ne} / \mathrm{N}$ ratio. Evolution, 59(7), 1596-

8491599 (2005).

850 Heide-Jørgensen, M. P., Härkönen, T., Aberg, P. Long term effects of epizootic in harbour seals 851 in the Kattegat-Skagerrak and adjacent areas. Ambio, 21, 511-516 (1992).

852 Herreman, J. K., Blundell, G. M., Ben-David, M. False sex-linked microsatellite primer for Phoca 853 vitulina. Mar. Mammal. Sci., 24, 411-413 (2008).

854 Herreman, J. K., Blundell, G. M., McDonald, D. B., Ben-David, M. Asymmetrical male-mediated

855 gene flow between Harbor seal (Phoca vitulina) populations in Alaska. Canadian J. Zool., 87, 856 498-507 (2009).

857 Hoban, S., Gaggiotti, O., Bertorelle, G. Sample Planning Optimization Tool for conservation and 858 population Genetics (SPOTG): a software for choosing the appropriate number of markers and 859 samples. Methods Ecol. Evol., 4, 299-303 (2013).

860 Hoelzel, A. R., Halley, J. M., O'Brien, S. J., Campagna, C. Elephant seal genetic variation and the 861 use of simulation models to investigate historical population bottlenecks. J. Hered., 84, 443-449 862 (1993).

863 Hoelzel, A. R, Goldsworthy, S. D., Fleischer, R. C. Population genetics. In Marine mammal 864 biology; An Evolutionary Approach. Edited by Hoelzel AR. Oxford: Blackwell Science, 325-352 865 (2002).

866 Jamieson, A., Taylor, S. C. S. Comparisons of three probability formulae for parentage exclusion. 867 Anim. Genet., 28, 397-400 (1997).

868 Jamieson, A. The effectiveness of using co-dominant polymorphic allelic series for (1) checking 869 pedigrees and (2) distinguishing full-sib pair members. Anim. Genet., 25 (Suppl. 1), 37-44 (1994). 870 Johnson, P. C. D., Haydon, D. T. Maximum likelihood estimation of allelic dropout and false allele 871 error rates from microsatellite genotypes in the absence of reference data. Genetics, 175, 827-42 872 (2007).

873 Jombart, T. adegenet: a R package for the multivariate analysis of genetic markers. Bioinformatics, 874 24, 1403-1405 (2008).

875 Jombart, T., Devillard, S., Balloux, F. Discriminant analysis of principal components: a new 876 method for the analysis of genetically structured populations. BMC Genetics 11, 94 (2010).

877 Jombart, T., Ahmed, I. adegenet 1.3-1: new tools for the analysis of genome-wide SNP data. 878 Bioinformatics (2011).

879 Jeffries, S., Huber, H., Calambokidis, J., Laake J. Trends and status of harbor seals in Washington 880 State: 1978-1999. The Journal of Wildlife Management, 207-218 (2003).

881 Kalinowski, S. T., Taper, M. L., Marshall, T. C. Revising how the computer program CERVUS 882 accommodates genotyping error increases success in paternity assignment. Mol. Ecol., 16, 10998831106 (2007).

884 King, T. L. Kalinowski, S. T., Schill, W. B., Spidle, A. P., Lubinski, B. A. Population structure of 885 Atlantic salmon (Salmo salar L.): a range-wide perspective from microsatellite DNA variation. 886 Mol. Ecol., 10, 807-821 (2001).

887 Kopelman, N. M., Mayzel, J., Jakobsson, M., Rosenberg, N. A., Mayrose, I. Clumpak: a program 888 for identifying clustering modes and packaging population structure inferences across K. Mol. 889 Ecol. Resour., 15, 1179-1191 (2015).

890 Lande, R. Mutation and conservation. Conserv. Biol.,9, 782-791 (1995). 
891 Lonsinger, R. C., Adams, J. R., Waits, L. P. Evaluating effective population size and genetic 892 diversity of a declining kit fox population using contemporary and historical specimens. Ecology 893 and Evolution, 8(23), 12011-12021 (2018).

894 Lonergan, M., Duck Duck, C., Thompson, D., Mackey, B. Using sparse survey data to investigate 895 the declining abundance of British harbour seals. Journal Zoology 271, 261-269 (2007).

896 Lotze, H. K., Worm, B. Historical baselines for large marine animals. Trends in ecology and 897 evolution 24, 254-262 (2009).

898 Luikart, G., Allendorf, F. W., Cornuet, J-M., Sherwin, W. B. Distortion of allele frequency 899 distributions provides a test for recent population bottlenecks. J. Hered., 89(3), 238-247 (1997).

900 Luikart, G., Cornuet, J. M. Empirical evaluation of a test for identifying recently bottlenecked 901 populations from allele frequency data. Conserv. Biol., 12, 228-237 (1998).

902 Nei, M. Genetic distance between populations. Am. Nat., 106, 283-292 (1972).

903 Nei, M. Estimation of average heterozygosity and genetic distance from a small number of 904 individuals. Genetics, 89, 583-590 (1978).

905 Newman, D., Pilson, D. Increased probability of extinction due to decreased genetic effective 906 population size: experimental populations of Clarkia pulchella. Evolution, the International 907 Journal of Organic Evolution, 51, 354-362 (1997).

908 Nikolic, N., Butler, J. R., Baglinière, J. L., Laughton, R., McMyn, I. A,, Chevalet, C. An 909 examination of genetic diversity and effective population size in Atlantic salmon populations. 910 Genet. Res., 91(6), 395-412 (2009).

911 Nikolic, N., Chevalet, C. Detecting past changes of effective population size. Evol. Appl., 912 published online: 16 Jun 2014, doi: 10.1111/eva.12170, DOI: 10.1111/eva.12170 (2014a).

913 Nikolic, N., Chevalet, C. VarEff. Variation of Effective size. Software VAREFF (package R in 914 file.zip) and the documentation. http://dx.doi.org/10.13155/28781, DOI: 10.13155/28781 (2014b).

915 Marshall, L. G., Webb, S. D., Sepkoski, J.J. Jr., Raup, D. M. Mammalian evolution and the great 916 american interchange. Science, 215(4538), 1351-7 (1982).

917 Matthiopoulos, J., Cordes, L., Mackey, B., Thompson, D., Duck, C., Smout, S., Caillat, M., 918 Thompson P. State-space modelling reveals proximate causes of harbour seal population declines.

919 Oecologia, 174, 151-162 (2014).McClenachan, L., Ferretti, F., Baum J.K. From archives to 920 conservation: why historical data are needed to set baselines for marine animals and ecosystems. 921 Conservation Letters, 5, 349-359 (2012).

922 Merritt, J. W., Auton, C. A., Firth, C. R. Ice-proximal glaciomarine sedimentation and sea-level 923 change in the Inverness Area, Scotland: a review of the deglaciation of a major ice stream of the 924

925

926

927

928

929

930

931

932 Olsen, M. T., Islas, V., Graves, J. A., Onoufriou, A., Vincent, C., Brasseur, S., Frie, A. K., Hall,

933 A. J. Genetic population structure of harbour seals in the United Kingdom and neighbouring 934 waters. Aquatic. Conserv.: Mar. Freshw. Ecosyst., 27, 839-845 (2017).

936 in Canadian polar bears. Mol. Ecol., 4, 347-354 (1995). 
937 Paetkau, D., Slade, R., Burden, M., Estoup, A. Direct, real-time estimation of migration rate using 938 assignment methods: a simulation-based exploration of accuracy and power. Mol. Ecol., 13, 5593965 (2004).

940 Palo, J. U., Mäkinen, H. S., Helles, E., Stenman, O., Väinölä, R. Microsatellite variation in ringed 941 seals (Phoca hispida): genetic structure and history of the Baltic sea population. Heredity, 86, 609$942617(2001)$.

943 Palo, J. U., Hyvärinen, H., Helle, E., Mäkinen, H. S., Väinölä, R. Postglacial loss of microsatellite 944 variation in the landlocked Lake Saimaa ringed seal. Conserv. Genet., 4, 117-128 (2003).

945 Palsbøll, P. J., Heide-Jørgensen, M. P., Dietz, R. Population structure and seasonal movements of 946 narwhals, Monodon monoceros, determined from mtDNA analysis. Heredity, 78, 284-292 (1997).

947 Palsbøll, P. J., Peery, M.Z., Olsen, M.T., Beissinger, S.R., Bérubé, M. Inferring recent historic 948 abundance from current genetic diversity. Molecular Ecology, 22, 22-40 (2013).

949 Palstra, F. P., Ruzzante D. E. Genetic estimates of contemporary effective population size: What 950 can they tell us about the importance of genetic stochasticity for wild population persistence? Mol. 951 Ecol., 17(15), 3428-3447 (2008).

952 Pastor, T., Garza, J. C., Allen, P., Amos, W., Aguilar, A. Low genetic variability in the highly 953 endangered Mediterranean monk seal. J. Heredity, 95, 291-300 (2004).

954 Peakall, R., Smouse, P. E. GENALEX 6: genetic analysis in Excel. Population genetic software 955

956

957 for teaching and research. Mol. Ecol. Notes, 6, 288-295 (2006).

Peakall, R., Smouse, P. E. GenAlEx 6.5: genetic analysis in Excel. Population genetic software for teaching and research-an update. Bioinformatics, 28, 2537-2539 (2012).

958 Peery, M. Z., Kirby, R., Reid, B. N., Stoelting, R., Doucet-Bëer, E., Robinson, S., Vásquez959 Carrillo, C., Pauli, J. N., Palsbøll, P. J. Reliability of genetic bottleneck tests for detecting recent 960 population declines. Mol. Ecol., 21, 3403-3418 (2012).

961 Pichler, F. B., Baker, C. S. Loss of genetic diversity in the endemic Hector's dolphin due to 962 fisheries-related mortality. P. Roy. Soc. Lond. B. Bio., 267, 97-102 (2000).

963 Piry, S., Luikart, G., Cornuet, J-M. Bottleneck: a program for detecting recent effective population 964 size reductions from allele data frequencies. J. Hered., 90, 502-503 (1999).

965 Piry, S., Alapetite, A., Cornuet, J-M., Paetkau, D., Baudouin, L., Estoup, A. GeneClass2: A 966 software for genetic assignment and first- generation migrant detection. J. Hered., 95, 536-539 967 (2004).

968 Pritchard, J. K., Stephens, P., Donnelly, P. Inference of population structure using multilocus

969

970

971

972 genotype data. Genetics, 155, 945-959 (2000).

Puechmaille, S. J. The program structure does not reliably recover the correct population structure when sampling is uneven: subsampling and new estimators alleviate the problem. Mol. Ecol. Resour., 16, 608-627 (2016).

973 Rannala, B., Mountain, J. L. Detecting immigration by using multilocus genotypes. P. Nat. Acad. 974 Sci. USA., 94, 9197-9221 (1997).

975 Raymond, M., Rousset, F. GENEPOP (version 1.2): population genetics software for exact tests 976 and ecumenicism. J. Heredity, 86, 248-249 (1995).

977 Reed, D. H., O'Gradya, J.J., Brook, B.W., Ballouc J.D., Frankhama, R.. Estimates of minimum 978 viable population sizes for vertebrates and factors influencing those estimates. Biol. Conserv., 113, 979 23-24 (2003).

980 Rick, T. C., Lockwood R. Integrating paleobiology, archeology, and history to inform biological 981 conservation. Conserv. Biol., 27, 45-54 (2013).Roman, J., Palumbi, S.R. Whales before whaling 982 in the North Atlantic. Science 301, 508-510 (2003). 
983 Rousset, F. Genepop'007: a complete reimplementation of the Genepop software for Windows and 984 Linux. Mol. Ecol. Resources, 8, 103-106 (2008).

985 Rozen, S., Skaletsky, H. J. Primer3 on the WWW for general users and for biologist programmers. 986 In: Krawetz S, Misener S (eds) Bioinformatics Methods and Protocols: Methods in Molecular 987 Biology. Humana Press, Totowa, NJ, 365-386 (2000).

988 Seppä, H., Bjune, A. E., Telford, R. J., Birks, H. J. B., Veski, S. Last nine- thousand years of 989 temperature variability in Northern Europe. Clim. Past., 5, 523-535 (2009).

990 Small, R. J. Differential movements by harbor seal pups in contrasting Alaska environments. Mar. 991 Mammal. Sci., 21(4), 671-694 (2005).

992 Swart, J. A A., Reijnders, P. J H., Van Delden, W. Absence of genetic variation in harbor seals 993 (Phoca vitulina) in the Dutch Wadden Sea and the British Wash. Conserv. Biol., 10, 289-293 994 (1996).

995 Thioulouse, J., Chessel, D., Dolédec, S., Olivier, J. M.. ADE-4: a multivariate analysis and 996 graphical display software. Statistics and Computing, 7, 75-83 (1997). Thompson, D, Duck, C.D., Morris, C.D., Russell, D.J.F. The status of harbour seals (Phoca vitulina) in the UK. Aquatic Conserv: Mar Freshw Ecosyst. 29, 40- 60 (2019).

999 Thompson, P. M., Hall, A. J. Seals and epizootics - what factors might affect the severity of mass mortalities? Mammal Rev., 23, 149-154 (1993).

1002 Thompson, P. M., Kovacs, K. M., McConnell, B. J. Natal dispersal of harbour seals (Phoca vitulina) from breeding sites in Orkney, Scotland. J. Zool., London, 234, 668-673 (1994).

1004 Thompson, P. M., Tollit, D.J., Wood, D., Corpe, H.M. Estimating harbour seal abundance and status in an estuarine habitat in north-east Scotland. J. Appl. Ecol., 34, 43-52 (1997a).

1006 Thompson, P., Tollit D., Corpe H., Reid R., Ross H. Changes in haematological parameters in relation to prey switching in a wild population of harbour seals. Functional Ecology, 11, 743-750 (1997b).

1008 Thompson, P., Corpe H., Reid R. Prevalence and intensity of the ectoparasite Echinophthirius horridus on harbour seals (Phoca vitulina): effects of host age and inter-annual variability in host food availability. Parasitology, 117, 393-403 (1998).

1011 Thompson, P. M, Van Parijs, S., Kovacs, K. M. Local declines in the abundance of harbour seals: implications for the designation and monitoring of protected areas. J. Appl. Ecol., 38, 117-125 (2001). Visser, K. G., Kumarev, V.P., Örvell, C., de Vries, P., Broeders, H.W.J., van de Bildt, M.W.G., Groen, J., Teppema, J.S., Burger, M.C., UytdeHaag, F.G.C.M., Osterhaus, A.D.M.E. Comparison of two morbilliviruses isolated from seals during outbreaks of distemper in north west Europe and Siberia. Arch. Virol., 111, 149-164 (1990). Waples RS, England PR. Estimating contemporary effective population size on the basis of linkage disequilibrium in the face of migration. Genetics, 189, 633-644 (2011).

1022 Wiig, O., Øien, N. Recoveries of common seals Phoca vitulina L. tagged along the Norwegian Weir, B. S., Cockerham, C. C. Estimating F-statistics for the analysis of population structure. Evolution, 38, 1358-1370 (1984). coast. Fauna Norvegica, A, 9, 51-52 (1988). Willi, Y., Van Buskirk, J., Hoffmann, A.A. Limits to the adaptive potential of small populations. Annu Rev Ecol Evol Syst, 37, 433-58 (2006).

1027 Genotypes. Genetics, 163, 1177-1191 (2003). 
1028 Wilson, L.J., Hammond, P.S. The diet of harbour and grey seals around Britain: Examining the 1029 role of prey as a potential cause of harbour seal declines. Aquatic Conserv: Mar Freshw

1030 Ecosyst. 29, 71- 85 (2019).

1031 Whitehead, H. Cultural selection and genetic diversity in matrilineal whales. Science, 282, 170810321711 (1998).

1033 Wright, S. Evolution in Mendelian populations. Genetics, 16, 97-159 (1931).

1034 Wright, S. Evolution and genetics of populations, Vol. 2. The theory of gene frequencies. 1035 University of Chicago Press, Chicago (1969). 
Figure 1

Figure 1

Figure 1. Mean geographic location of the three areas sampled (Dornoch - 13 individuals, Cromarty - 12 individuals and Inverness - 68 individuals) from Moray Firth in north-east Scotland.

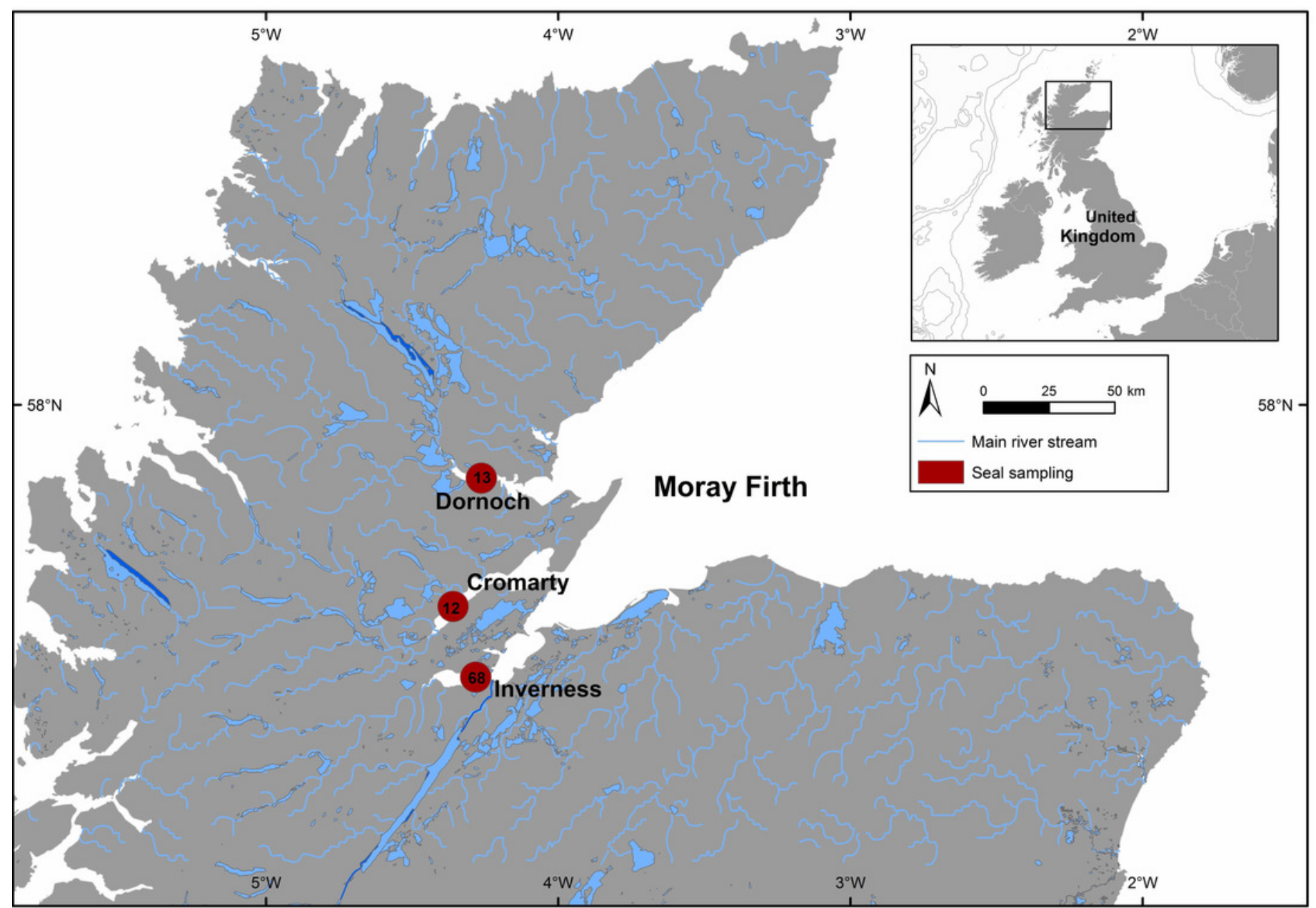


Figure 2

Figure 2

Figure 2. Probability of Identity for each Locus (PI) and for Increasing Combinations (PIsibs) with the 17 polymorphic microsatellite markers genotyped on harbour seals in the Moray Firth.

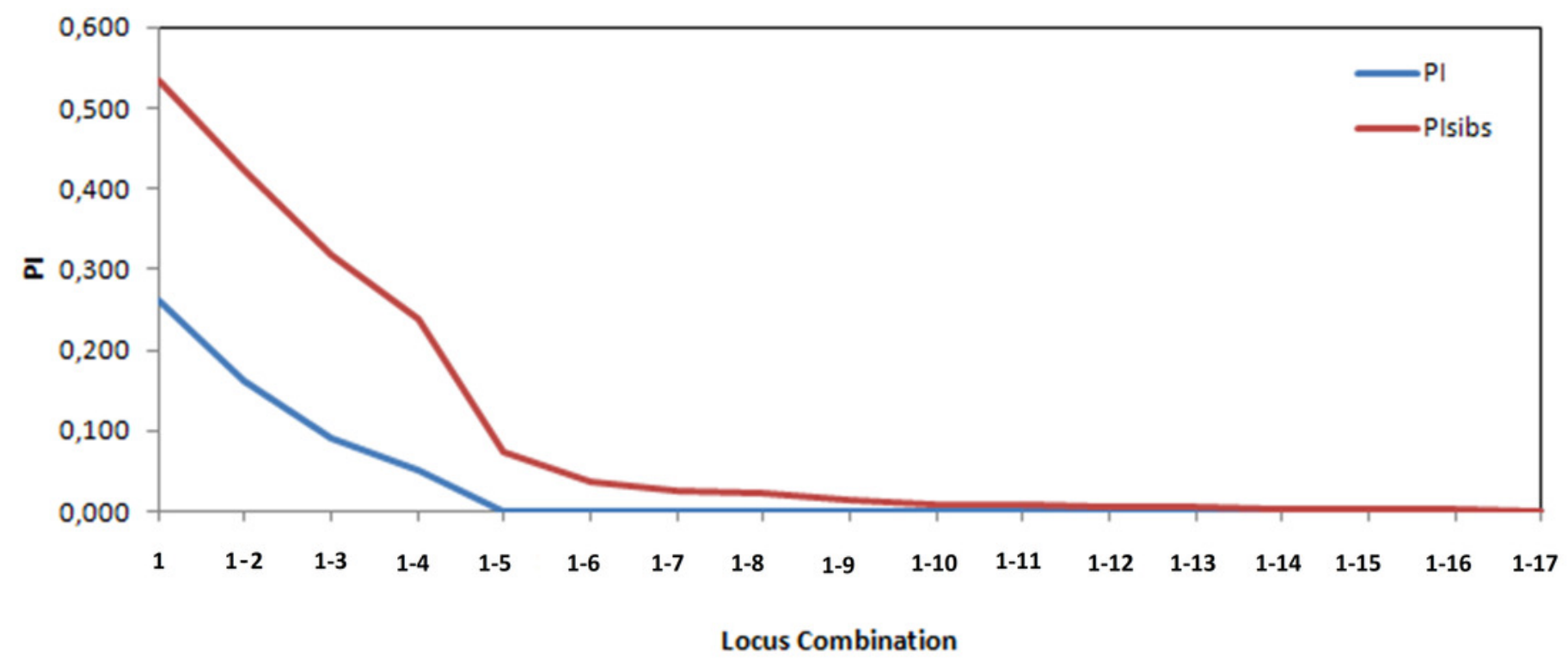




\section{Figure 3}

Figure 3

Figure 3. Effective size $(\mathrm{Ne})$ of harbour seals in the north-east UK (from Moray Firth genetic group) as a function of past generation time $(G)$ using 17 microsatellites (VarEff analysis). AArithmetic (red) and harmonic (green) mean, mode (blue), and median (black) from sampling time (0) to 30,000 generations ago. B- Posterior densities at the past generation time (G): 2,000 (black), 3,000 (blue), 4,000 (red), 5,000 (green), 6,000 (grey), 7,000 (purple), 8,000 (orange), 9,000 (pink), and 10,000 (red) generations ago. C- Posterior densities at the past generation time (G) 10,000 (black), 20,000 (blue), 30,000 (red), 40,000 (blue), 50,000 (grey), 60,000 (purple), 70,000 (orange), 80,000 (green), 90,000 (brown), and 100,000 (red) generations ago.
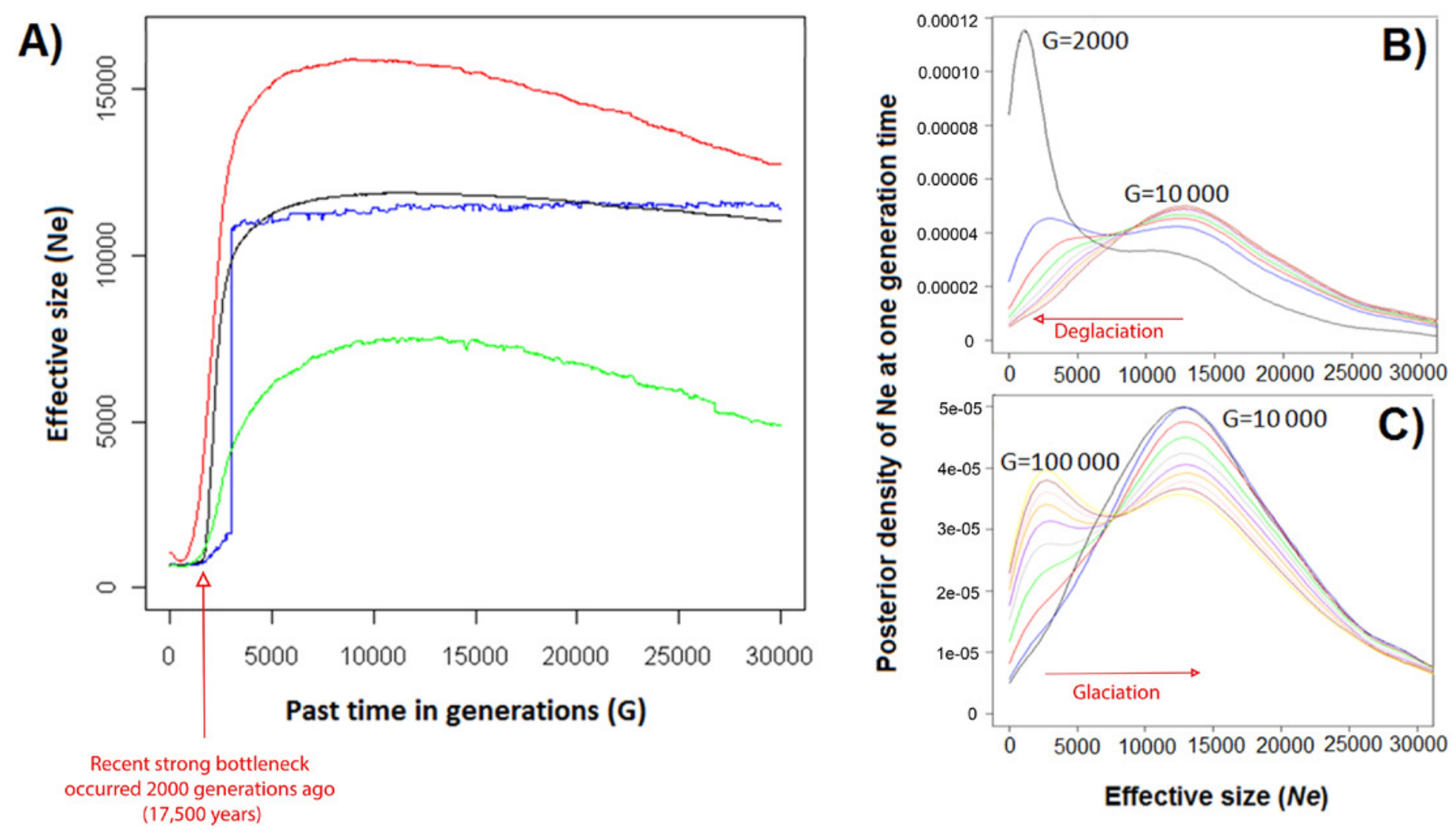
Figure 4

Figure 4

Figure 4. Harbour seal's effective size (harmonic mean of the posterior distribution, VarEff analysis) within Moray Firth (using 17 microsatellites) in generation time (from 0 to 1,000 generations ago) (A) and in calendar years (from 1995 (sampling date) to 500 AD (B). The arrows represent the main trends: reduction (red) and increase (blue). Figure B shows the latest tendency enlarged, the last red arrow.

A)

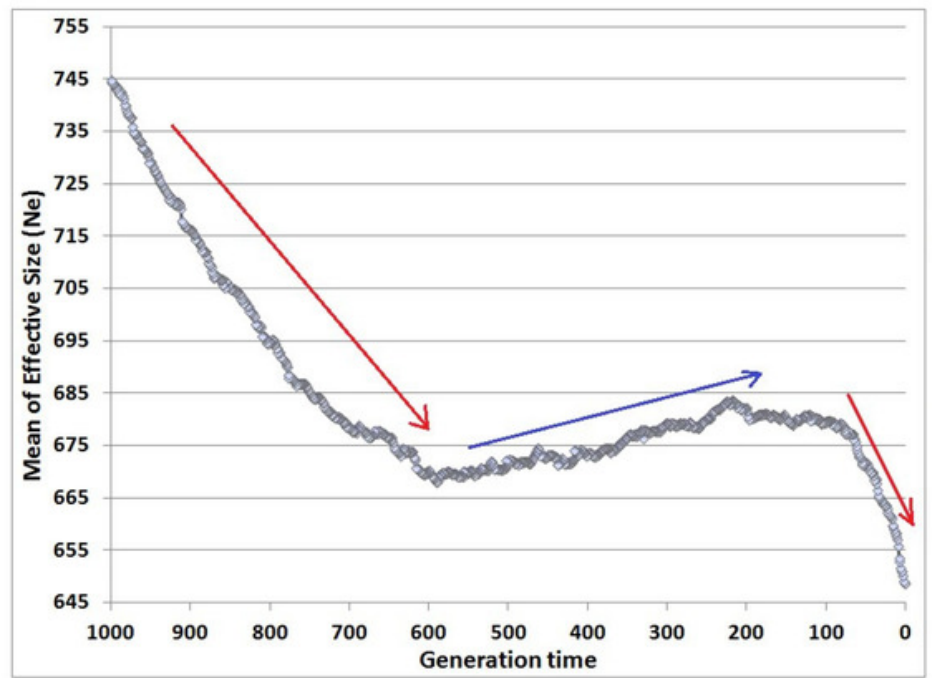

B)

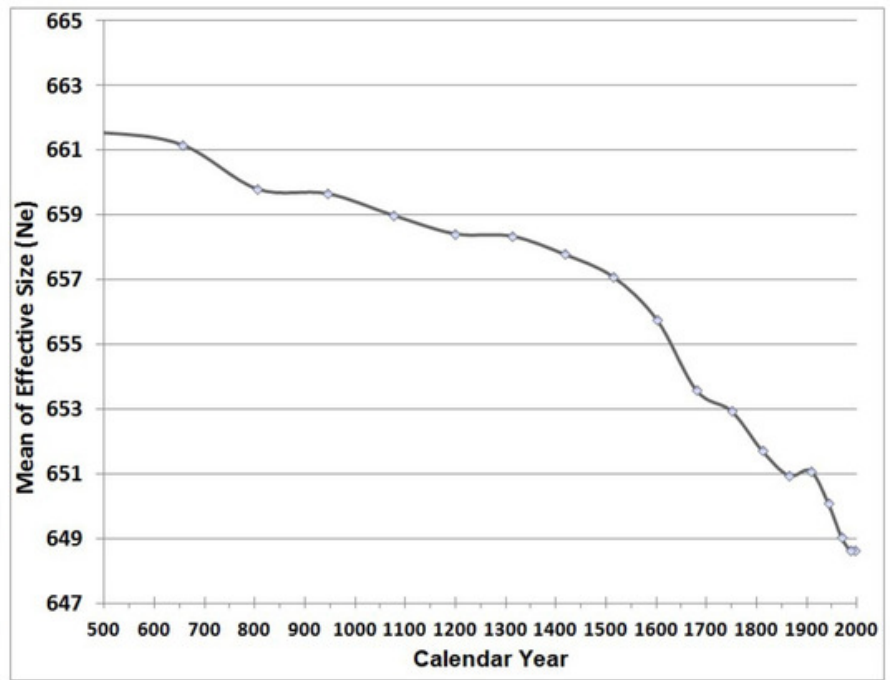


Figure 5

Figure 5

Figure 5. Posterior distribution of the Time to Most Recent Common Ancestor allele (TMRCA, VarEff analysis). Suggested coalescent events are given as generation numbers (middle column) and as years (right column) for harbour seals in the Moray Firth (Scotland). Each peak (left figure) represents a potential bottleneck.

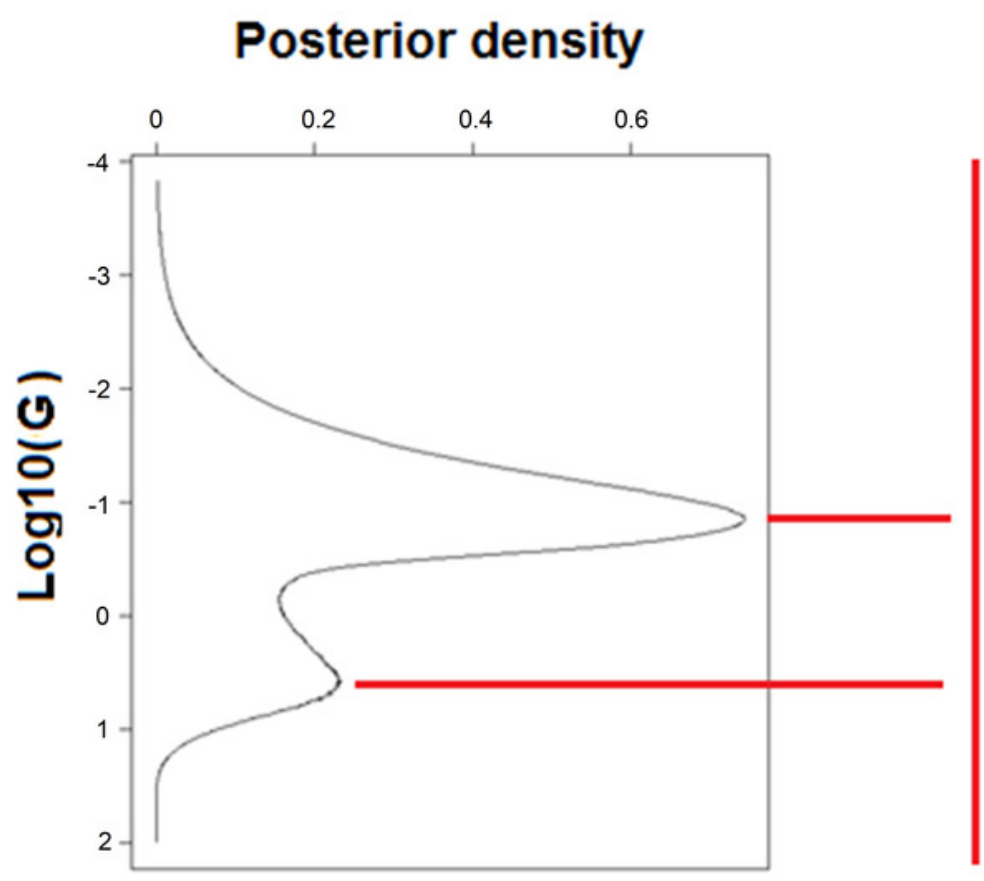

Coalescent event Generations

800

30000
Years

7000

262500 


\section{Table $\mathbf{1}$ (on next page)}

Table 1.

Summary statistics of the 17 microsatellite markers selected for Harbour seals (Phoca vitulina). Sample sizes per locus (S). Number of alleles (A). Expected (He), unbiased Nei's ${ }^{95}$ expected (H.n.b) and observed (HO) heterozygosity. Hardy-Weinberg equilibrium (HWE) pvalues (P) with the standard error in parentheses. Polymorphism information content (PIC). Probability of identity (PI). Probability of parentage exclusion (PE1, single parent; PE2, a second parent given a first parent assigned; PE3, a pair of parents). Null allele frequency (Fnull). Number of repeated genotypes (Nrep and percentage (\%) of the total number of individuals genotyped for each loci). Genotyping error rate per allele, E1 referring to allelic dropout rate and E2 to the false allele rate, and the $95 \%$ confidence interval (CI). Significant values are highlighted in bold $(\mathrm{P}<0.05)$ for heterozygote excess. 
Table 1. Summary statistics of the 17 microsatellite markers selected for Harbour seals (Phoca vitulina). Sample sizes per locus (S). Number of alleles (A). Expected (He), unbiased Nei's ${ }^{95}$ expected (H.n.b) and observed (Ho) heterozygosity. Hardy-Weinberg equilibrium (HWE) p-values (P) with the standard error in parentheses. Polymorphism information content (PIC). Probability of identity (PI). Probability of parentage exclusion (PE1, single parent; PE2, a second parent given a first parent assigned; PE3, a pair of parents). 5 Null allele frequency (Fnull). Number of repeated genotypes (Nrep and percentage (\%) of the total number of individuals genotyped for 6 each loci). Genotyping error rate per allele, E1 referring to allelic dropout rate and E2 to the false allele rate, and the 95\% confidence 7 interval $(\mathrm{CI})$. Significant values are highlighted in bold $(\mathrm{P}<0.05)$ for heterozygote excess.

\begin{tabular}{|c|c|c|c|c|c|c|c|c|c|c|c|c|c|c|c|}
\hline \multirow[b]{2}{*}{ Locus } & \multirow[b]{2}{*}{$\mathbf{s}$} & \multirow[b]{2}{*}{ A } & \multirow[b]{2}{*}{$\mathrm{He}$} & \multirow[b]{2}{*}{ H.n.b } & \multirow[b]{2}{*}{ Ho } & \multirow[b]{2}{*}{$\mathbf{P}$} & \multirow[b]{2}{*}{ PIC } & \multirow[b]{2}{*}{ PI } & \multirow[b]{2}{*}{ PE1 } & \multirow[b]{2}{*}{ PE2 } & \multirow[b]{2}{*}{ PE3 } & \multirow[b]{2}{*}{ Fnull } & \multirow[b]{2}{*}{ Nrep(\%) } & \multicolumn{2}{|c|}{ Genotyping error rate } \\
\hline & & & & & & & & & & & & & & E1 (Cl 95\%) & E2 (Cl 95\%) \\
\hline SGPV9 & 85 & 3 & 0.277 & 0.279 & 0.329 & $0.254(0.00038)$ & 0.242 & 0.558 & 0.038 & 0.123 & 0.205 & 0.023 & $10(12)$ & $0.00(0.00-0.41)$ & $0.00(0.00-0.07)$ \\
\hline SGPV11 & 92 & 3 & 0.275 & 0.276 & 0.174 & $0.002(0.00004)$ & 0.240 & 0.561 & 0.038 & 0.122 & 0.203 & 0.107 & $10(11)$ & $0.00(-0.00-0.78)$ & $0.00(0.00-0.07)$ \\
\hline SGPV17 & 92 & 3 & 0.409 & 0.411 & 0.413 & $0.019(0.00013)$ & 0.345 & 0.413 & 0.084 & 0.184 & 0.292 & 0.039 & $10(11)$ & $0.00(-0.00-0.20)$ & $0.00(-0.00-0.07)$ \\
\hline SGPV10 & 90 & 2 & 0.231 & 0.232 & 0.267 & $0.352(0.00047)$ & 0.204 & 0.618 & 0.027 & 0.102 & 0.174 & 0.026 & $10(11)$ & $0.00(0.00-0.40)$ & $0.00(-0.00-0.07)$ \\
\hline SGPV16 & 74 & 14 & 0.886 & 0.892 & 0.919 & $0.659(0.00033)$ & 0.876 & 0.023 & 0.628 & 0.772 & 0.921 & 0.013 & $10(14)$ & $0.00(0.00-0.08)$ & $0.00(-0.00-0.07)$ \\
\hline PVC19 & 93 & 2 & 0.350 & 0.352 & 0.344 & $1.000(0.00000)$ & 0.289 & 0.484 & 0.061 & 0.144 & 0.229 & 0.039 & $10(11)$ & $0.00(-0.00-0.19)$ & $0.00(0.00-0.07)$ \\
\hline PVC30 & 82 & 4 & 0.493 & 0.496 & 0.476 & $0.767(0.00037)$ & 0.388 & 0.362 & 0.122 & 0.204 & 0.310 & 0.039 & $10(12)$ & $0.00(-0.00-0.21)$ & $0.00(0.00-0.07)$ \\
\hline PVC78 & 93 & 4 & 0.243 & 0.245 & 0.204 & $0.003(0.00005)$ & 0.219 & 0.597 & 0.030 & 0.113 & 0.193 & 0.058 & $10(11)$ & $0.00(-0.00-0.19)$ & $0.00(0.00-0.07)$ \\
\hline GS7 & 93 & 2 & 0.157 & 0.158 & 0.172 & $1.000(0.00000)$ & 0.145 & 0.723 & 0.012 & 0.072 & 0.129 & 0.033 & $10(11)$ & $0.00(-0.00-0.71)$ & $0.00(0.00-0.07)$ \\
\hline GS2 & 91 & 3 & 0.173 & 0.174 & 0.165 & $0.557(0.00049)$ & 0.163 & 0.694 & 0.015 & 0.086 & 0.156 & 0.047 & $10(11)$ & $0.00(-0.00-0.25)$ & $0.00(0.00-0.07)$ \\
\hline GS3 & 93 & 4 & 0.560 & 0.563 & 0.570 & $0.579(0.00048)$ & 0.491 & 0.262 & 0.158 & 0.294 & 0.442 & 0.022 & $10(11)$ & $0.00(-0.00-0.16)$ & $0.00(0.00-0.07)$ \\
\hline $\mathrm{H} 12$ & 93 & 5 & 0.614 & 0.617 & 0.613 & $0.901(0.00025)$ & 0.550 & 0.213 & 0.194 & 0.345 & 0.504 & 0.029 & $10(11)$ & $0.00(-0.00-0.09)$ & $0.00(0.00-0.07)$ \\
\hline HL2O & 90 & 2 & 0.043 & 0.044 & 0.044 & $1.000(0.00000)$ & 0.043 & 0.916 & 0.001 & 0.021 & 0.041 & 0.050 & $9(10)$ & $0.70(-0.03-1.81)$ & $0.00(-0.00-0.14)$ \\
\hline HL15 & 93 & 3 & 0.242 & 0.243 & 0.237 & $0.707(0.00043)$ & 0.215 & 0.601 & 0.029 & 0.109 & 0.186 & 0.042 & $10(11)$ & $0.00(-0.00-0.76)$ & $0.00(0.00-0.07)$ \\
\hline OrrFCB2 & 90 & 4 & 0.547 & 0.550 & 0.633 & $0.070(0.00022)$ & 0.489 & 0.263 & 0.151 & 0.296 & 0.449 & 0.016 & $10(11)$ & $0.00(-0.00-0.11)$ & $0.00(-0.00-0.07)$ \\
\hline OrrFCB1 & 79 & 2 & 0.013 & 0.013 & 0.013 & $1.000(0.00000)$ & 0.012 & 0.927 & 0.001 & 0.019 & 0.037 & 0.055 & $10(13)$ & $0.70(-0.03-1.81)$ & $0.00(0.00-0.12)$ \\
\hline OrrFCB24 & 90 & 3 & 0.510 & 0.513 & 0.956 & $0.000(0.00000)$ & 0.391 & 0.359 & 0.130 & 0.202 & 0.303 & 0.009 & $9(10)$ & $0.00(0.00-0.08)$ & $0.00(-0.00-0.08)$ \\
\hline an & 89 & 3.7 & 0.354 & 0.356 & 0.384 & $.522(0.000)$ & 0.312 & & & & & & & & \\
\hline
\end{tabular}




\section{Table 2 (on next page)}

Table 2.

Mean (arithmetic), median and standard deviation of present (No) and ancestral ( $\mathrm{Na}$ ) effective population size, the mutation rate $(\mu)$, and ancestral time in years $(T f)$ of Harbour seals in Moray Firth (left part, MSVAR analysis). Mean (arithmetic and harmonic), median and standard deviation (Sd) of present (No) and the estimated size 5.000 generations ago (N5000), and the global present ( <!--[if !msEquation]--> <!--[if !vml]--> <!--[endif]--><!-[endif]-->) and ancestral estimate ( $<$ !--[if !msEquation]--> <!--[if !vml]--> $<$ !--[endif]--><!-[endif]-->a) (rifht part, VarEff analysis). 
1 Table 2. Mean (arithmetic), median and standard deviation of present ( $\mathrm{No}$ ) and ancestral $(\mathrm{Na})$ 2 effective population size, the mutation rate $(\mu)$, and ancestral time in years $(T f)$ of Harbour seals 3 in Moray Firth (left part, MSVAR analysis). Mean (arithmetic and harmonic), median and standard 4 deviation $(\mathrm{Sd})$ of present $(\mathrm{No})$ and the estimated size 5.000 generations ago (N5000), and the global 5 present $(\hat{N} o)$ and ancestral estimate $(\hat{N} a)$ (rifht part, VarEff analysis).

6

\begin{tabular}{|l|rrrr|rr|r|r|}
\cline { 2 - 9 } \multicolumn{1}{c|}{} & \multicolumn{4}{c|}{ MSVAR } & \multicolumn{4}{c|}{ VarEff } \\
\cline { 2 - 9 } \multicolumn{1}{c|}{} & \multicolumn{1}{c|}{$N o$} & \multicolumn{1}{c|}{$N a$} & $\mu$ & \multicolumn{1}{c|}{ No } & N5000 & \multicolumn{1}{c|}{$\hat{N} o$} & $\hat{N} a$ \\
\hline Mean & 1669 & 342874 & 0.00018 & 96416 & 988 and 649 & 14824 & & \\
Median & 821 & 128186 & 0.00010 & 37235 & 714 & 11298 & 1287 & 64826 \\
Sd & 2979 & 846836 & 0.00026 & 219518 & 2089 & 23055 & & \\
\hline
\end{tabular}

7

8 